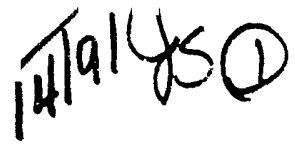 \\ SANDIA REPORT
}

SAND91-0862 $-U C-233$

Unlimited Release

Printed June 1991

\section{Structural Analysis of a Reflux Pool-Boiler Solar Receiver}

\author{
Edward L. Hoffman, Charles M. Stone
}

Prepared by

Sandia National Laboratories

Albuquerque, New Mexico 87185 and Livermorn, California 94550

for the United States Department of Energy

under Contract DE-AC04-76DP00789 
Issued by Sandia National Laboratories, operated for the United States Department of Energy by Sandia Corporation.

NOTICE: This report was prepared as an account of work sponsored by an agency of the United States Government. Neither the United States Government nor any agency thereof, nor any of their employees, nor any of their contractors, subcontractors, or their employees, makes any warranty, express or implied, or assumes any legal liability or responsibility for the accuracy, completeness, or usefulness of any information, apparatus, product, or process disclosed, or represents that its use would not infringe privately owned rights. Reference herein to any specific commercial product, process, or service by trade name, trademark, manufacturer, or otherwise, does not necessarily constitute or imply its endorsement, recommendation, or favoring by the United States Government, any agency thereof or any of their contractors or subcontractors. The views and opinions expressed herein do not necessarily state or reflect those of the United States Government, any agency thereof or any of their contractors.

Printed in the United States of America. This report has been reproduced directly from the best available copy.

Available to DOE and DOE contractors from

Office of Scientific and Technical Information

PO Box 62

Oak Ridge, TN 37831

Prices available from (615) 576-8401, FTS 626-8401

Available to the public from

National Technical Information Service

US Department of Commerce

5285 Port Royal Rd

Springfield, VA 22161

NTIS price codes

Printed copy: $\mathrm{A} 0.3$

Microfiche copy: A01 
SAND91-0862

SAND- -91-0862

Unlimited Release

Printed June, 1991

DE92 002211

\title{
Structural Analysis of a Reflux Pool-Boiler Solar Receiver
}

\author{
Edward L. Hoffman \\ Charles M. Stone \\ Engineering and Structural Mechanics Division \\ Sandia National Laboratories \\ Albuquerque, New Mexico 87185
}

\begin{abstract}
Coupled thermal-structural finite element calculations of a reflux pool-boiler solar receiver were performed to characterize the operating stresses and to address issues affecting the service life of the receiver. Analyses performed using shell elements provided information for receiver material selection and design optimization. Calculations based on linear elastic fracture mechanics principles were performed using continuum elements to assess the vulnerability of a seam-weld to fatigue crack growth. All calculations were performed using ABAQUS, a general purpose finite element code, and elements specifically formulated for coupled thermal-structural analysis. Two materials were evaluated: 316L SS and Haynes 230 alloys. The receiver response was simulated for a combination of structural and thermal loads that represent the startup and operating conditions of the receiver. For both materials, maximum stresses in the receiver developed shortly after startup due to uneven temperature distribution across the receiver surface. The largest effective stress was near yield in the $316 \mathrm{~L}$ SS receiver and below 39 percent of yield in the Haynes 230 receiver. The calculations demonstrated that significant stress reductions (over 25 percent) could be obtained by reducing the aft dome thickness to one closer to the absorber. The fatigue calculations demonstrated that the stress distribution near the seam-weld notch depends primarily on the structural load created by internal pressurization of the receiver rather than the thermal loads, indicating that the thermal loads can be neglected when assessing the stress intensity near the seam-weld notch. The stress intensity factor, computed using the J-integral method and crack opening-displacement field equations, was shown to be significantly below the fatigue threshold for most steels. Furthermore, the calculations indicated that the weld notch was always loaded in compression, a condition which is not conducive to fatigue crack growth.
\end{abstract}

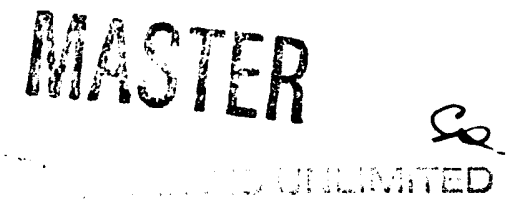




\section{Acknowledgments}

The authors would like to acknowledge G. W. Wellman for his generous support and guidance in the fracture mechanics aspects of this analysis. 


\section{Contents}

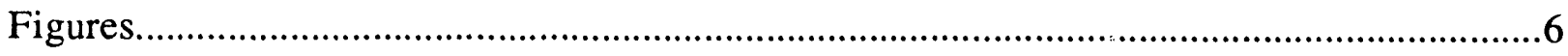

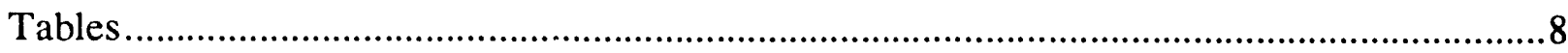

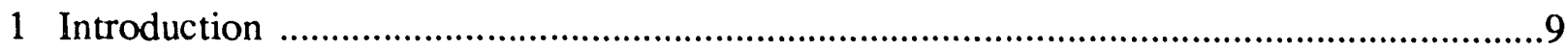

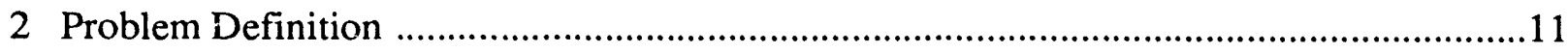

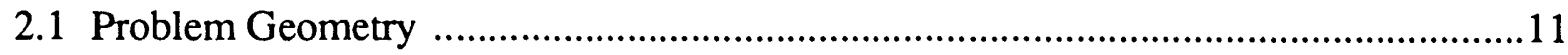

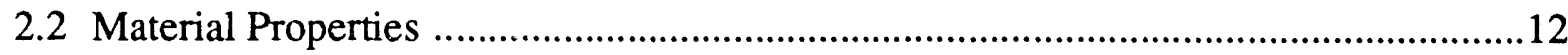

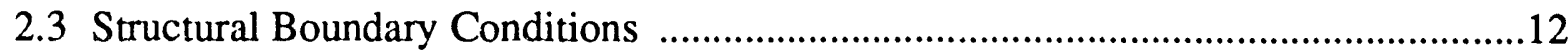

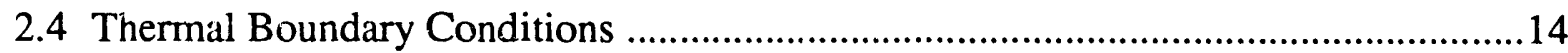

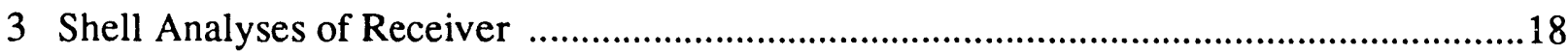

3.1 Details of Finite Element Analyses ……….......................................................18

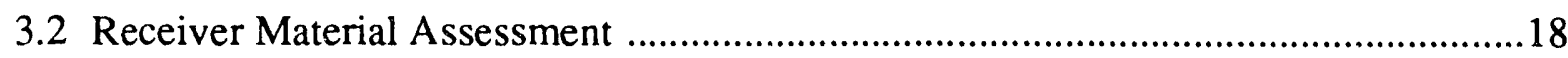

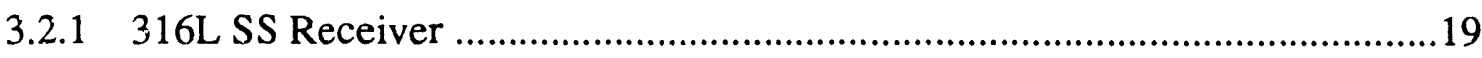

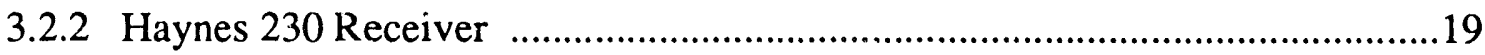

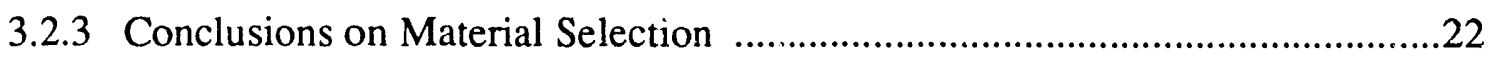

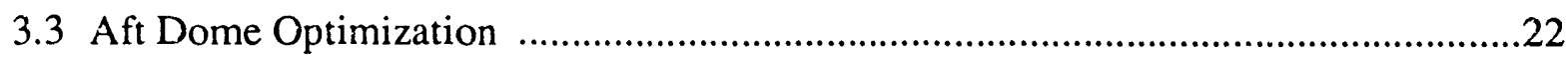

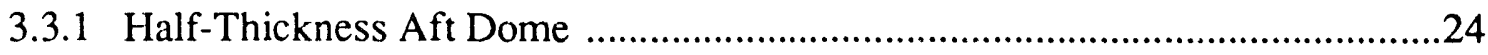

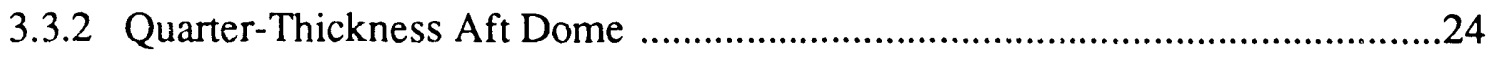

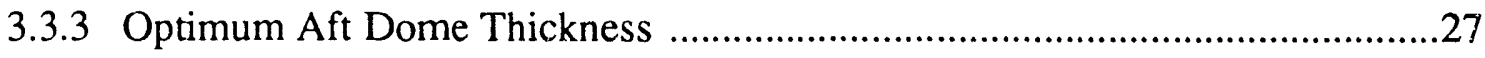

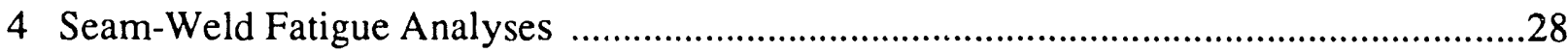

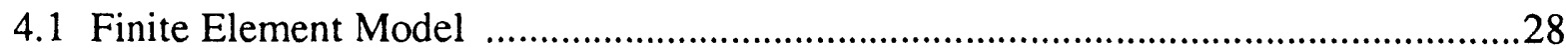

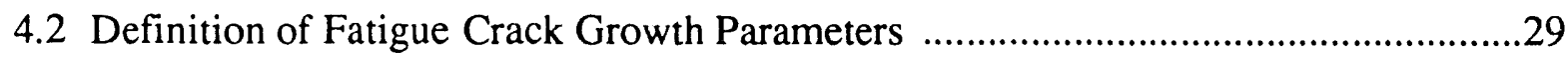

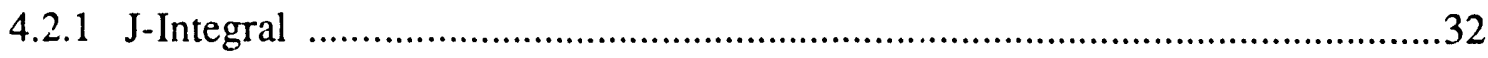

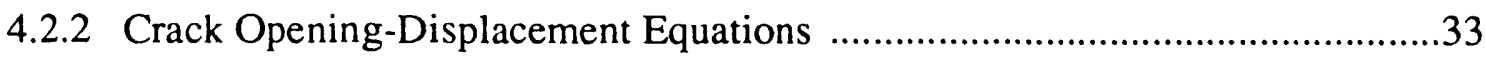

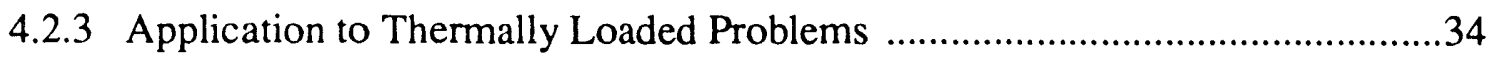

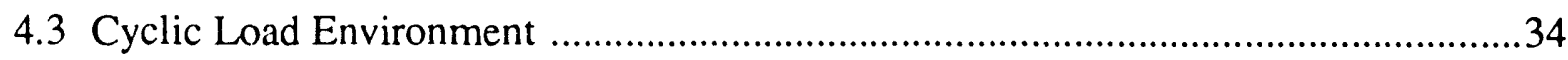

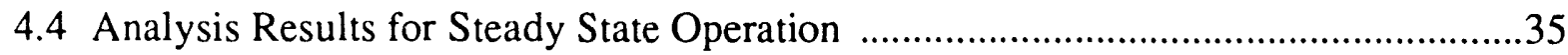

4.4.1 Case 1: On-Sun Structural and Thermal Loading ………..............................35

4.4.2 Case 2: On-Sun Structural Loading and No Thermal Loads ...........................38

4.4.3 Case 3: Off-Sun Structural Loading with Reversed On-Sun Thermal Loads ..40

4.4.4 Case 4: Off-Sun Structural Loading with No Thermal Loads ........................42

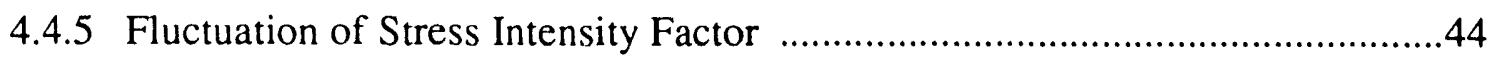

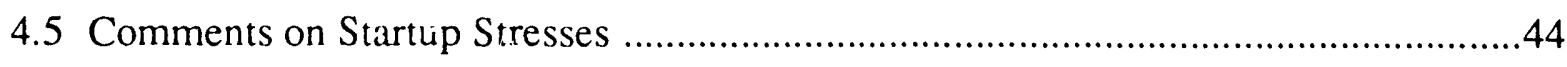

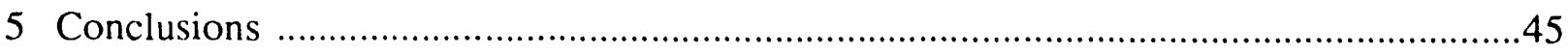

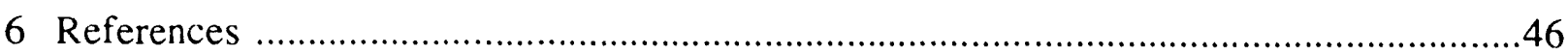

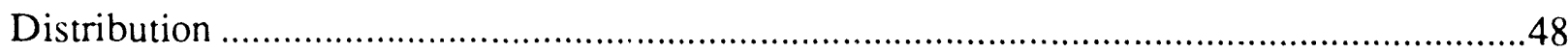




\section{Figures}

1. Schernatic of the reflux pool-boiler receiver [8] .......................................... 10

2. Geometric detail of the reflux pool-boiler receiver. ..............................................11

3. (a) Structural boundary conditions used for the reflux pool-boiler receiver analyses.

(b) Definition of the surface position variable, $s$, used for the presentation of results.

4. Thermal boundary conditions used for the reflux pool-boiler receiver analysis.

5. Assumed absorber and aft dome outer surface temperature profiles as a function of surface position (see Figure $3 b$ ) for startup operating conditions.

6. Computed incident solar flux distribution assumed for the startup and steady state operating conditions as a function of the radial coordinate of the receiver.

7. Absorber and aft dome inner temperature profiles for startup and steady state operating conditions.

8. Absorber and aft dome outer temperature profiles for startup and steady state operating conditions.

9. Receiver meridional and circumferential stress profiles during Step 3 of the receiver startup for 316L SS.

10. Receiver meridional and circumferential stress profiles during steady state operation (Step 7) for 316L SS.

11. Receiver meridional and circumferential stress profiles during Step 3 of the receiver startup for Haynes 230.

12. Receiver meridional and circumferential stress profiles during steady state operation (Step 7) for Haynes 230.

13. Receiver meridional and circumferential stress profiles during Step 3 of the receiver startup for Haynes 230 and a half-thickness $(1.59 \mathrm{~mm})$ aft dome.

14. Receiver meridional and circumferential stress profiles during steady state (Step 7) operation for Haynes 230 and a half-thickness $(1.59 \mathrm{~mm})$ aft dome.

15. Receiver meridional and circumferential stress profiles during Step 3 of the receiver startup for Haynes 230 and a quarter-thickness $(0.813 \mathrm{~mm})$ aft dome.

16. Receiver meridional and circumferential stress profiles during steady state operation for Haynes 230 and a quarter-thickness $(0.813 \mathrm{~mm})$ aft dome.

17. Cross section of a candidate seam-weld joining the absorber and aft dome of the reflux pool-boiler receiver.

18. Finite element mesh of the reflux pool-boiler receiver.

19. Focused mesh used at seam-weld notches [7].

20. Schematic representation of fatigue-crack growth data [12] . .............................31

21. Crack-tip region, coordinate system and path independent J-integral. 
22. Temperature at the outer surface of the absorber calculated using axisymmetric shell elements and 8-node axisymmetric solid elements for on-sun structural and therrinal loading (Case 1).

23. Circumferential stress in absorber calculated using axisymmetric shell elements and 8-node axisymmetric solid elements for on-sun structural and thermal loading (Case 1).

24. Largest principal stress near the weld discontinuity for the case of thermal loading and $\left(\mathrm{P}_{\text {amb }}-\mathrm{P}_{\text {int }}\right)=32.9 \mathrm{kPa}$ (Case 1$)$.

25. Circumferential stress in absorber for on-sun structural loading and no thermal loads (Case 2).

26. Largest principal stress near the weld discontinuity for the case of no thermal loading and $\left(\mathrm{P}_{\text {amb }}-\mathrm{P}_{\text {int }}\right)=32.9 \mathrm{kPa}$ (Case 2).

27. Circumferential stress in the absorber as a function of surface position for off-sun structural and reversed thermal loading (Case 3).

28. Largest principal stress near the weld discontinuity for the case of reversed thermal loading and $\left(\mathrm{P}_{\mathrm{amb}}-\mathrm{P}_{\mathrm{int}}\right)=84.1 \mathrm{kPa}$ (Case 3$)$.

29. Circumferential stress in the absorber as a function of surface position for the case of off-sun structural loading and no thermal loads (Case 4).

30. Largest principal stress near the weld discontinuity for the case of no thermal loading and $\left(\mathrm{P}_{\mathrm{amb}}-\mathrm{P}_{\mathrm{int}}\right)=84.1 \mathrm{kPa}$ (Case 4$)$. 


\section{Tables}

1. Temperature Dependent Elastic Moduli Used for the Pool-Boiler Receiver Analyses.

2. Temperature Dependent Thermal Conductivity Used for the Pool-Boiler Receiver Analyses.

3. Temperature Dependent Coefficient of Thermal Expansion Used for the Pool-Boiler Receiver Analyses. 


\section{Introduction}

Sandia National Laboratories, together with the U. S. Department of Energy, has identified Stirling Dish-Electric systems as having potential to meet long-term program goals in solar energy [1]. In the solar dish-electric concept, a receiver absorbs energy reflected from a parabolic mirror which tracks the sun. Thermal energy from the receiver is used to drive an engine, which powers an electric generator. Many types of conversion devices have been considered for dish-electric systems; however, the Stirling engine is of greatest interest because it has exceptionally high thermodynamic efficiency [2]. The term reflux is used to describe the method by which thermal energy is transferred to the Stirling engine. In a reflux receiver, a liquid metal functions as an intermediate heat transfer fluid between the solar absorber and the heater tubes of the Stirling engine. This intermediate fluid is contained in an evacuated vessel and vaporized from the backside of the solar absorber. The vapor condenses on the Stirling engine heat tubes, releasing the latent heat, and then passively returns to the backside of the solar absorber due to gravity (refluxing). Pool-boiling assures that there is sufficient inventory of liquid metal to completely wet the absorber surface and establish a convective current.

A prototype sodium reflux pool-boiler receiver, developed at Sandia National Laboratories by the Solar Thermal Electric Technology Division (6217), was recently tested on-sun. Figure 1 is a schematic of the Sandia-developed reflux pool-boiler receiver. The solar receiver dish consists of two 316L stainless steel spherical domes, the absorber and aft-dome, edge-welded together to form a hermetically sealed hollow dish. The space between the absorber and aft-dome contains liquid sodium. The receiver's sodium inventory of 12.7 pounds ensures that the entire absorber surface will be wetted in all dish orientations. During current on-sun testing, the Stirling engine has been replaced by a cold water calorimeter for controlled heat extraction. The operating environment exposes the receiver to transient temperatures ranging from $20^{\circ} \mathrm{C}$ to $820^{\circ} \mathrm{C}$. The loading is cyclic with at least 10,000 startup/shutdown cycles expected during the design lifetime. In addition to the thermal loads, the receiver is subject to a cyclic change in internal pressure between zero and one-half atmosphere absolute. The receiver must contain the liquid sodium which will burn when exposed to air. Detailed knowledge of the thermal stresses induced in the absorber is needed to design the receiver to operate for its 30-year lifetime.

As an intermediate step in the development of a next-generation receiver, two changes in the original design have been considered: using Haynes 230 alloy which is more creep resistant than $316 \mathrm{~L}$ stainless steel, and replacing the edge-weld with a seam-weld. Design requirements of this intermediate design include maximizing thermal efficiency while optimizing structural performance and component life. The Solar Thermal Electric Technology Division requested that the Engineering and Structural Mechanics Division (1514) provide structural analysis support for the reflux pool-boiler receiver project. Coupled temperature-displacement analyses have been performed for receiver material selection, design optimization, and issues that affect the lifetime of the receiver $[3,4,5,6]$. All calculations were performed using ABAQUS, a general purpose finite element code, and elements specifically formulated for coupled thermalstructural analysis [7]. Analyses performed using shell elements provided information for re- 


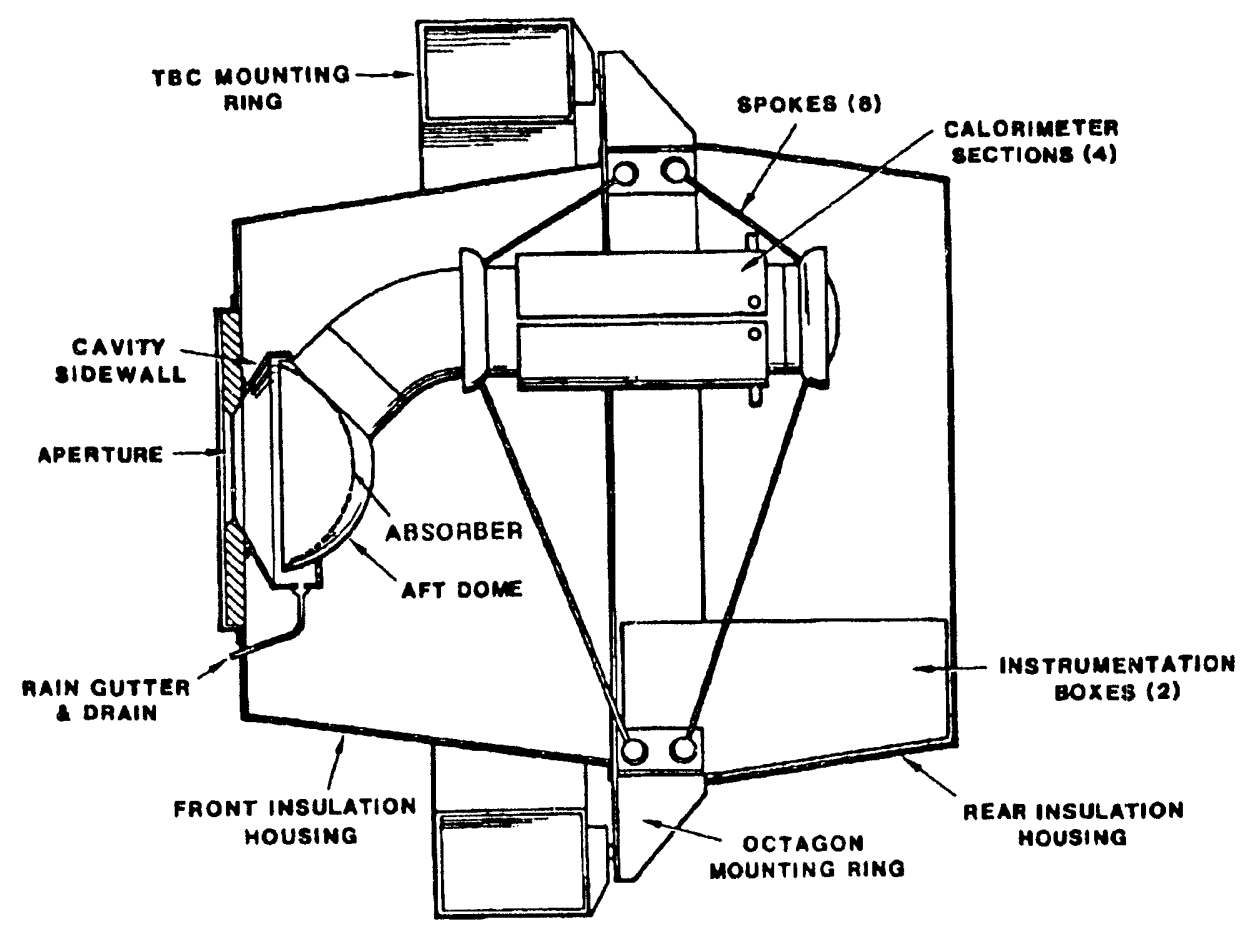

Figure 1. Schematic of the reflux pool-boiler receiver [8].

ceiver material selection and design optimization. Calculations based on linear elastic fracture mechanics principles were performed using continuum elements to assess the vulnerability of the proposed seam-weld to fatigue crack growth. These analyses, coupled with results of developmental testing, are intended to assess the performance of the prototype receiver and to assist in the development of a next-generation receiver.

This report documents and summarizes the results of structural analyses performed for and presented to the Solar Thermal Electric Technology Division. The next section provides a general description of the problem, including geometrical assumptions, material properties, and boundary conditions. Section 3 presents coupled thermal-structural analyses performed with shell elements. These calculations characterize the overall receiver stresses and address optimization issues. A critical issue in assessing the life of the receiver is the fatigue strength of the seam weld which joins the absorber and aft dome [9]. Section 4 presents a more detailed fatigue analysis of this seam-weld. Finally, conclusions and recommendations are presented in Section 5. 


\section{Problem Definition}

\subsection{Problem Geometry}

Figure 2 shows the idealized geometry and dimensions used for modeling the reflux poolboiler receiver. The receiver model consists of the absorber, which is a spherical dome with a 219-mm radius and a 70.2-degree half angle, and the aft dome which is another spherical dome with a $208-\mathrm{mm}$ radius. The design gap between the domes is nominally $34.3 \mathrm{~mm}$. The thickness of the absorber is $0.813 \mathrm{~mm}$ compared to $3.18 \mathrm{~mm}$ for the aft dome. In the prototype receiver, the absorber is edge-welded to the aft dome around its outer circumference. A seamweld has been proposed as a change to the original design.

The receiver assembly is supported by a 203-mm-diameter pipe (see Figure 1) designed to mate with a cold water calorimeter for controlled power extraction. Since the primary interest was in receiver response to thermal loads, the pipe mount was not included in the finite element models. There is no differential expansion between these components because the support pipe is constructed of the same material as the receiver. However, the bending moment imposed by the support pipe on the aft dome is neglected in this simplification. This assumption allowed for an axisymmetric representation of the receiver.

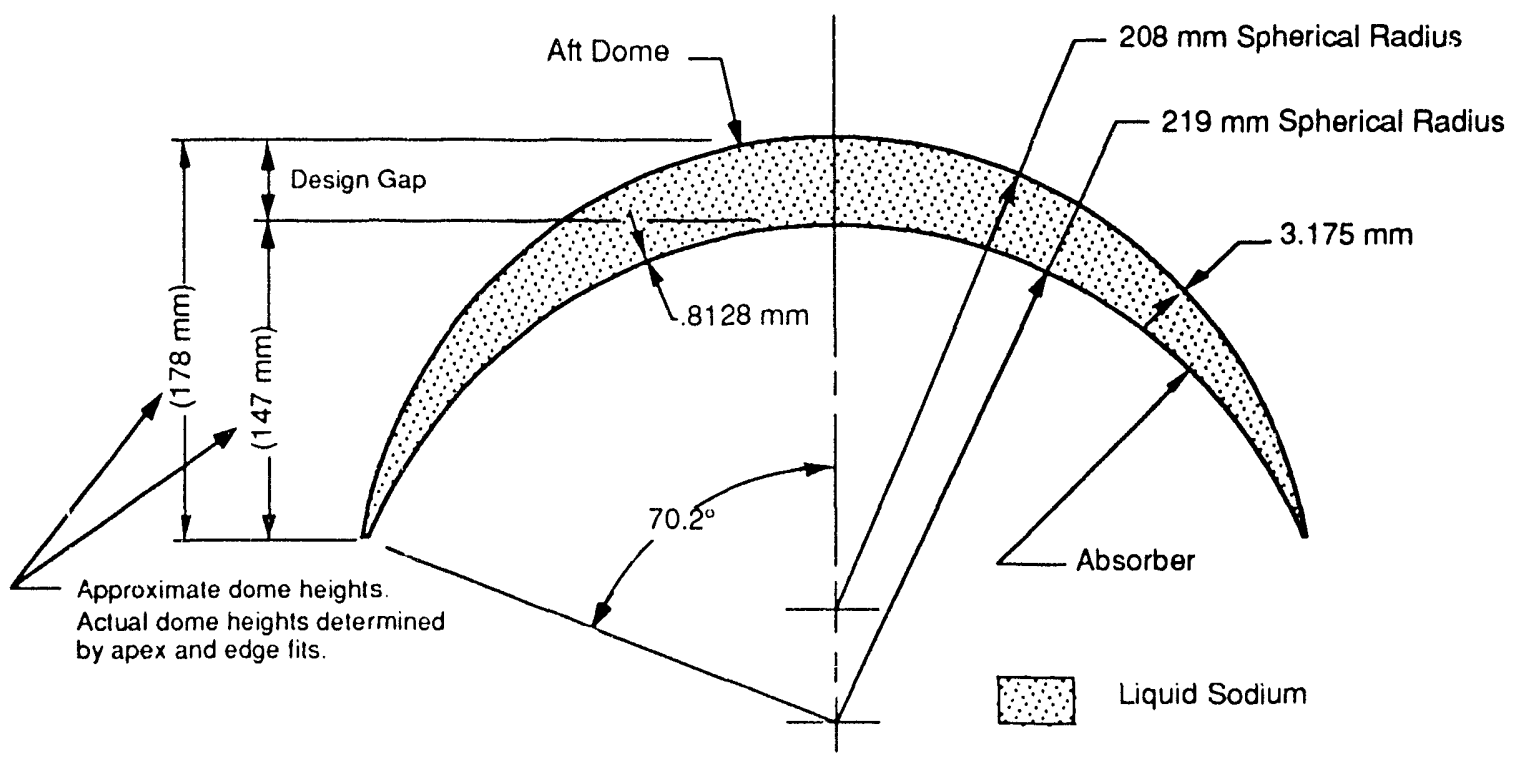

Figure 2. Geometric detail of the reflux pool-boiler receiver. 


\subsection{Material Properties}

The prototype receiver currently undergoing on-sun testing is constructed of $316 \mathrm{~L}$ stainless steel, but plans call ror a next-generation receiver to be constructed of Haynes 230 steel which is more creep resistant than $316 \mathrm{~L} \mathrm{SS}$. Both materials were modeled as linear-elastic with temperature dependent material properties. The material properties, specified as functions of temperature, are the elastic modulus presented in Table 1, the thermal conductivity in Table 2, and the coefficient of thermal expansion in Table 3. A temperature independent Poisson's ratio of 0.3 was used for both alloys, and yield stresses of 103 and $260 \mathrm{MPa}$ were used for 316L SS and Haynes 230 at $800^{\circ} \mathrm{C}$, respectively.

\subsection{Structural Boundary Conditions}

The structural boundary conditions used in the analyses are shown schematically in Figure 3a. Radial displacements of the absorber and aft dome are specified to be zero at the axis of symmetry. The centerline node on the back surface of the aft dome is constrained in both the axial and radial directions to remove axial rigid body deformation from the problem. The coordinate $s$, denoting surface position on the receiver and afi dome, is defined in Figure $3 b$. This parameter will be used later for presentation of temperature data and analysis results.

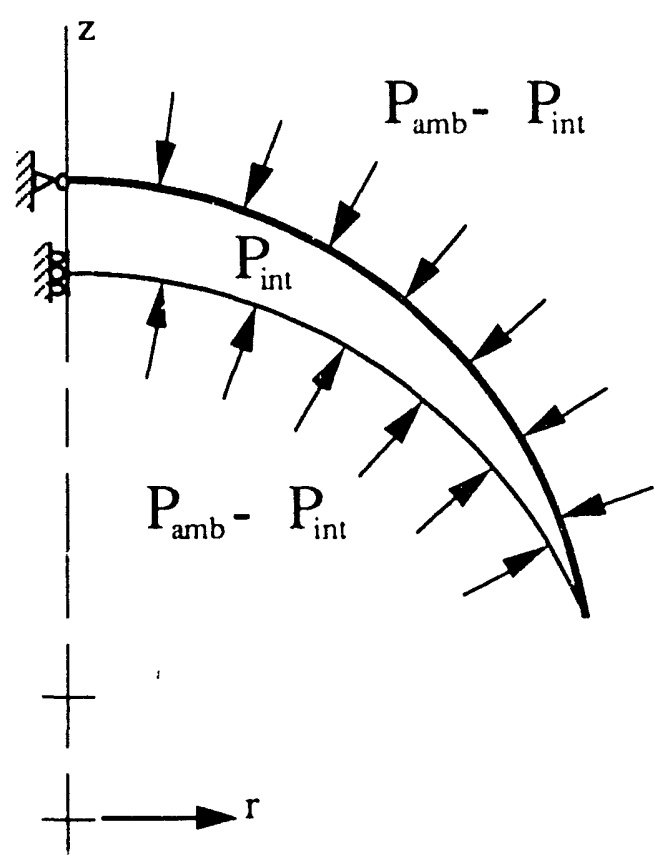

(a)

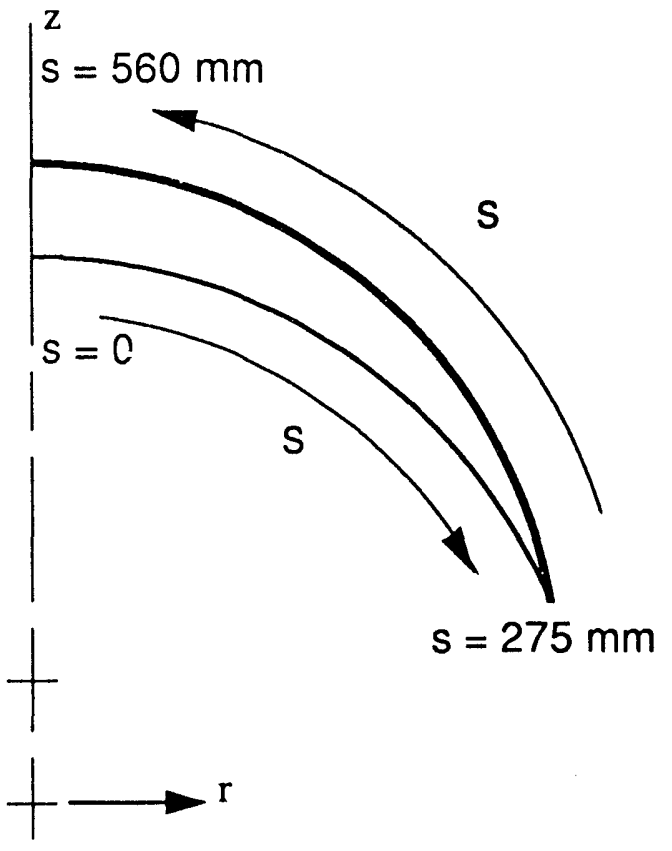

(b)

Figure 3. (a) Structural boundary conditions used for the reflux pool-boiler receiver analyses. (b) Definition of the surface position variable, $s$, used for the presentation of results. 
Table 1. Temperature Dependent Elastic Moduli Used for the Pool-Boiler Receiver Analyses.

\begin{tabular}{||c|c|c||}
\hline Temperature $\left({ }^{\circ} \mathrm{C}\right)$ & $\begin{array}{c}316 \mathrm{~L} \\
\text { Elastic Modulus }(\mathrm{GPa})\end{array}$ & $\begin{array}{c}\text { Haynes 230 } \\
\text { Elastic Modulus (GPa) }\end{array}$ \\
\hline 100 & 190.1 & 207 \\
200 & 184.0 & 202 \\
300 & 176.7 & 196 \\
400 & 168.3 & 190 \\
500 & 159.9 & 184 \\
600 & 149.1 & 177 \\
700 & 138.6 & 171 \\
800 & 126.1 & 164 \\
\hline
\end{tabular}

Table 2. Temperature Dependent Thermal Conductivity Used for the Pool-Boiler Receiver Anályses.

\begin{tabular}{||c|c|c||}
\hline Temperature $\left({ }^{\circ} \mathrm{C}\right)$ & $\begin{array}{c}316 \mathrm{~L} \\
\text { Conductivity }(\mathrm{W} / \mathrm{m} \mathrm{K})\end{array}$ & $\begin{array}{c}\text { Haynes 230 } \\
\text { Conductivity }(\mathrm{W} / \mathrm{m} \mathrm{K})\end{array}$ \\
\hline 100 & 14.7 & 10.4 \\
200 & 16.34 & 12.4 \\
300 & 17.94 & 14.4 \\
400 & 19.48 & 16.4 \\
500 & 20.96 & 18.4 \\
600 & 22.39 & 20.4 \\
700 & 23.76 & 22.4 \\
800 & 25.07 & 24.4 \\
\hline
\end{tabular}

Table 3. Temperature Dependent Coefficient of Thermal Expansion Used for the PoolBoiler Receiver Analyses.

\begin{tabular}{||c|c|c||}
\hline Temperature $\left({ }^{\circ} \mathrm{C}\right)$ & $\begin{array}{c}316 \mathrm{~L} \\
\text { Coefficient of Thermal } \\
\text { Expansion }\left(\times 10^{-6}{ }^{\circ} \mathrm{C}^{-1}\right)\end{array}$ & $\begin{array}{c}\text { Haynes 230 } \\
\text { Coefficient of Thermal } \\
\text { Expansion }\left(\times 10^{-6}{ }^{\circ} \mathrm{C}^{-1}\right)\end{array}$ \\
\hline 100 & 15.8 & 12.7 \\
200 & 16.7 & 13.0 \\
300 & 17.2 & 13.3 \\
400 & 17.8 & 13.7 \\
500 & 18.3 & 14.0 \\
600 & 18.6 & 14.4 \\
700 & 18.9 & 14.8 \\
800 & 19.2 & 15.2 \\
\hline
\end{tabular}


To represent loading induced by the pressure differential between the liquid sodium and the surrounding atmosphere, a uniform pressure boundary condition was applied to the aft dome and absorber as shown in Figure 3a. The external pressure, $\mathrm{P}_{\mathrm{amb}}$, represents the local ambient pressure $(84.1 \mathrm{kPa}$ in Albuquerque, $\mathrm{NM})$, while $\mathrm{P}_{\mathrm{int}}$ is the absolute pressure of the liquid sodium given by the following equation [10]

$$
\log \mathrm{P}_{\mathrm{int}}=6.354-\frac{5567}{\mathrm{~T}}-0.5 \log \mathrm{T}
$$

where $T$ is the sodium absolute temperature in Kelvin $(\mathrm{K})$ and $\mathrm{P}_{\text {int }}$ is in standard atmospheres. According to Equation (1), the internal pressure, $\mathrm{P}_{\mathrm{int}}$, is zero absolute at amient temperature $(300 \mathrm{~K})$ and increases with increasing temperature. Consequently, the applied pressure $\left(\mathrm{P}_{\mathrm{amb}}{ }^{-}\right.$ $\mathrm{P}_{\text {int }}$ ) is initially $84.1 \mathrm{kPa}$ (approximately $1 \mathrm{~atm}$.) when the receiver is off-sun, and decreases to an on-sun steady state value of $32.9 \mathrm{kPa}$ (approximately $0.5 \mathrm{~atm}$.) at $800^{\circ} \mathrm{C}$.

\subsection{Therm?l Boundary Conditions}

The thermal model of the receiver utilizes temperature data taken from thermocouples at discrete points on the outer surfaces of the absorber and aft dome as well as a computed incident solar flux distribution. The absorber thermocouple data have not been corrected for the effect of the incident solar flux, and are estimated to be up to $20^{\circ} \mathrm{C}$ higher than the absorber temperature, depending on the flux level. The convention illustrated in Figure 4 is used to denote the two sides of the aft dome and the absorber shells. The inner surfaces of the shells are in contact with the liquid sodium (internal to the sodium containment), while the outer surfaces are exposed to the atmosphere. During startup (Figure 4a), temperatures are defined on the outer surface of the absorber where they were measured, and the solar flux is applied on the inner surface where the temperatures were not known. Aft dome temperatures, also measured on the outer surface of the receiver, are assumed constant through the shell thickness. The assumed temperature profile of the receiver, shown in Figure 5, is based on temperature data measured at six discrete locations on the prototype receiver. The data are presented as a function of the surface distance coordinate $s$ defined in Figure 3b. Each temperature data point represents the average of four measurements made at $90^{\circ}$ intervals at the same surface position on the receiver. The temperature data were linearly interpolated between the data points. The spatially varying flux distribution, shown in Figure 6, was calculated using CIRCE2 [11], a computer code for calculating incident solar flux distributions of point-focus concentrators. For each absorber element, the flux data were entered into the analysis as a function of the radial coordinate of the element. The sodium temperature used to calculate the internal pressure in Equation (1) was assumed equal to the temperature at the aft dome axis of symmetry.

When steady state operating conditions are reached (Figure 4b), a constant temperature boundary condition of $811.5^{\circ} \mathrm{C}$ is specified on the inner surface of the absorber, and the spatially varying flux distribution in Figure 6 is specified on the outer surface of the absorber. The temperature specification during this phase of operation was moved to the inner surface 


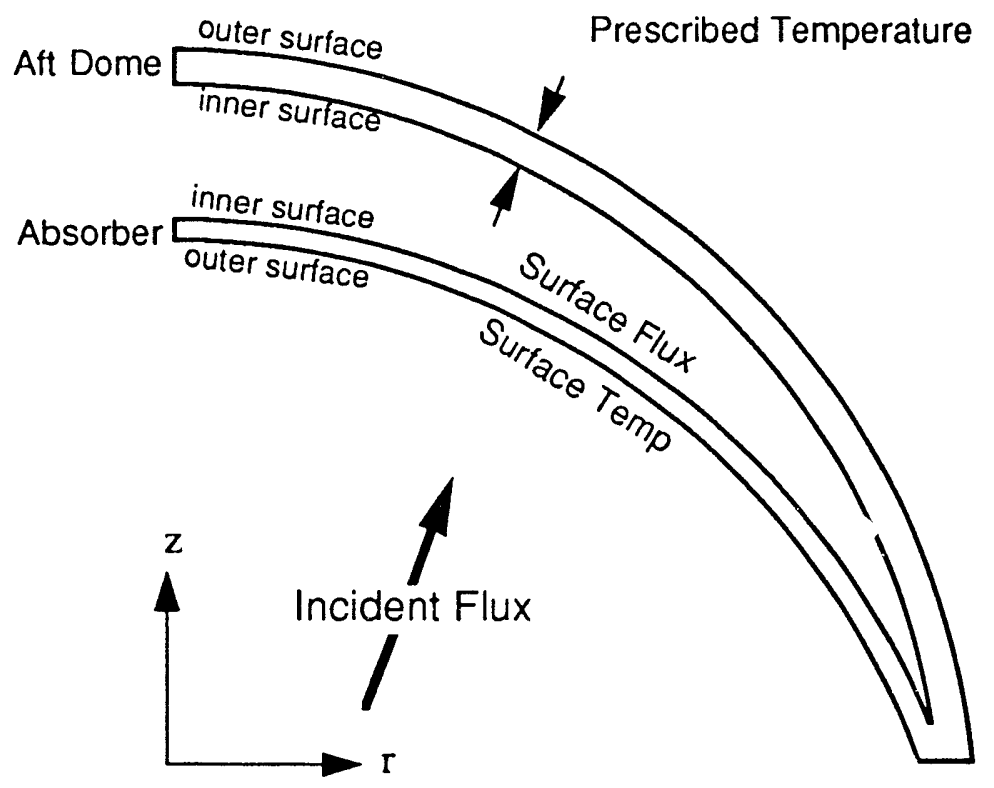

(a) Startup Phase

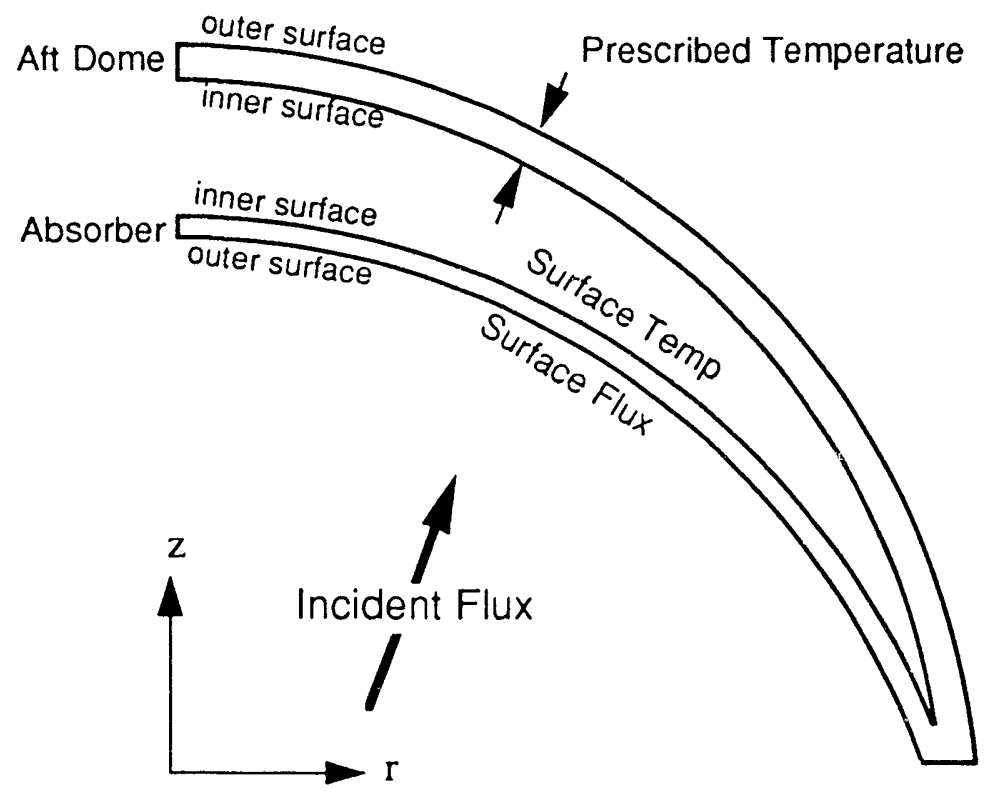

(a) Steady State Phase

Figure 4. Thermal boundary conditions used for the reflux pool-boiler receiver analysis. 


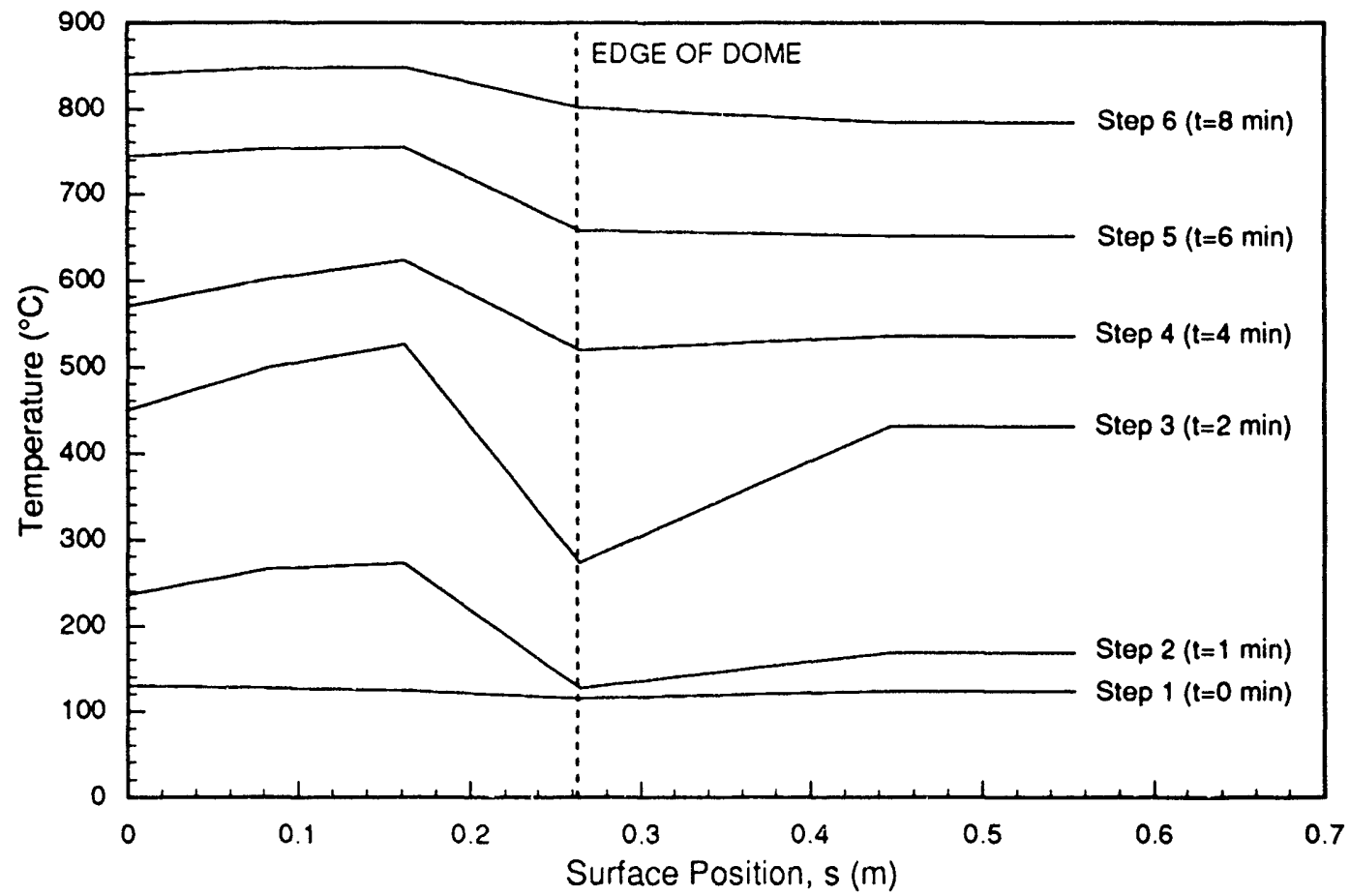

Figure 5. Assumed absorber and aft dome outer surface temperature profiles as a function of surface position (see Figure 3b) for startup operating conditions.

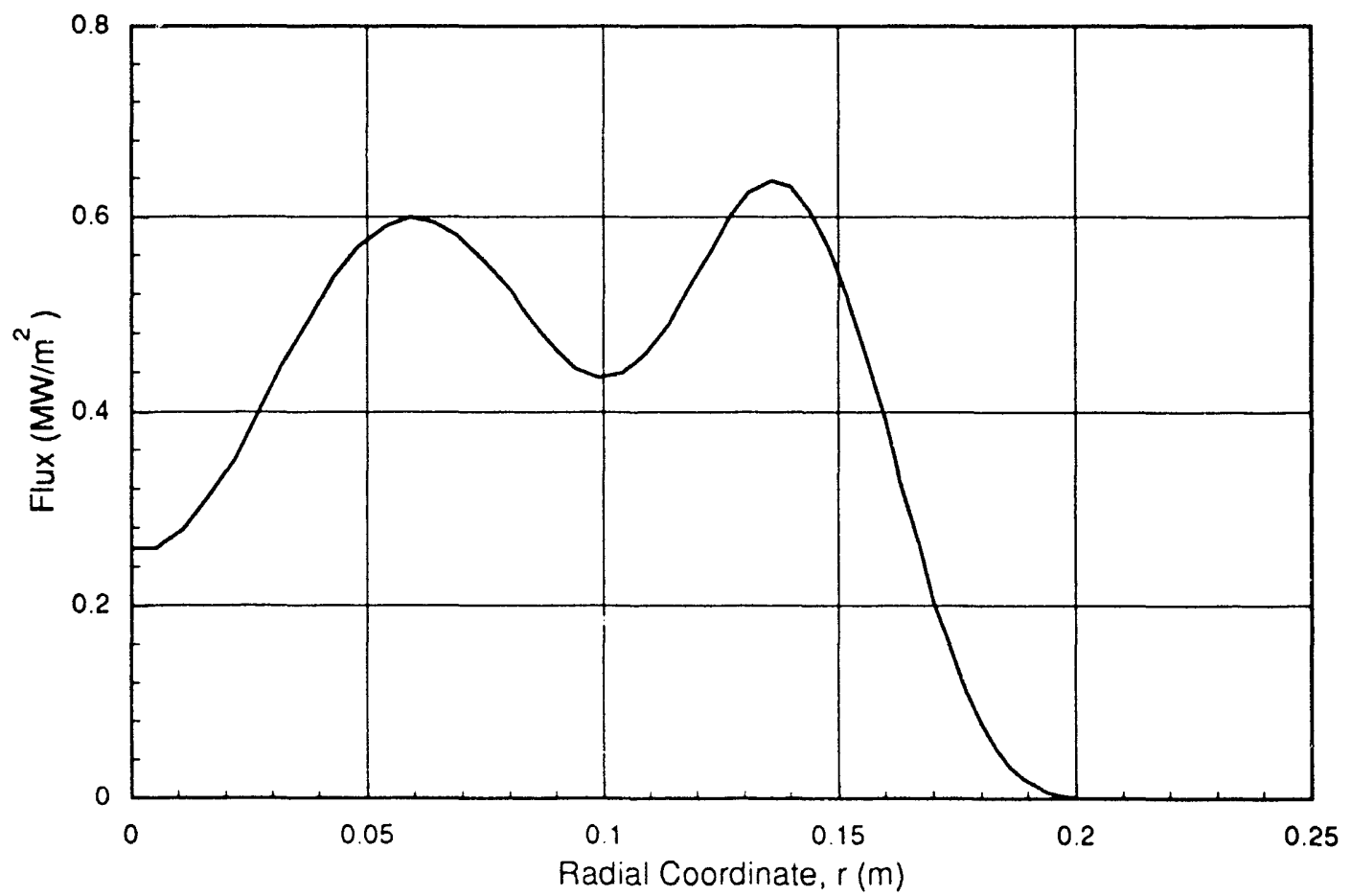

Figure 6. Computed incident solar flux distribution assumed for the startup and steady state operating conditions as a function of the radial coordinate of the receiver. 
because an estimate of the wall temperature can be made at the sodium/wall interface based on the measured bulk sodium temperature (assumed to be uniform) and the estimated wall superheat. The aft dome is subjected to a constant temperature boundary condition of 811.5 ${ }^{\circ} \mathrm{C}$ through the thickness of the shell. 


\section{Shell Analyses of Receiver}

Coupled thermal-structural calculations were performed with an axisymmetric shell model of the receiver. The calculations were performed to characterize the stress generated by heating the receiver during startup and steady state operation. Both 316L SS and Haynes 230 were considered. Furthermore, the same model was used to investigate the effects of aft dome thickness reductions in a Haynes 230 receiver. Reducing the aft dome thickness would result in a significant savings in material costs. The analyses were performed for both startup and steady state phases of operation. The following sections present the details of the finite element model, the receiver material assessment calculations, and the aft dome optimization study.

\subsection{Details of Finite Elemen i Analyses}

The geometry assumptions and load conditions discussed in the preceding section allowed the use of an axisymmetric model of the receiver. The model was constructed using 80 threenoded axisymmetric shell elements developed specifically for coupled thermal-structural analyses. These elements use quadratic interpolation for the geometry and displacements while the temperatures are linearly interpolated from the end nodes and piecewise quadratically through the shell thickness. Five integration points through the shell thickness were specified for all calculations.

During startup, the six temperature distributions shown in Figure 5 were individually and sequentially applied and the solutions were obtained independently as quasi-steady state solutions. The steady state operating phase of the receiver is analyzed as a seventh steady state solution. The quasi-steady state assumption is appropriately based on the thermal diffusivity of the material, the absorber wall thickness, and the relatively long times involved in the startup process. The receiver reacts much more rapidly to transient external conditions compared to the time required to start the receiver ( 9 minutes). As a result, transient effects are negligible. For each solution, the thermal strains are calculated from an initial reference temperature of $20^{\circ} \mathrm{C}$.

\subsection{Receiver Material Assessment}

Although each nodal point has temperatures computed at five points through the shell, only the temperatures at the inner and outer surfaces are presented for all seven time steps. In addition, stress output from the axisymmetric shell elements is provided in the form of meridional and circumferential stresses at the inner and outer surfaces. The stress results are presented for Steps 3 and 7 for each analysis because the largest stresses are generated at Step 3 of startup, and Step 7 corresponds to steady state on-sun operation. Both the temperature and stress results are presented as a function of the surface distance coordinate, $s$, defined in Figure $3 \mathrm{~b}$. 


\subsubsection{L SS Receiver}

The nodal temperatures computed along the inner and outer surfaces of the 316L SS receiver are shown in Figure 7 and Figure 8, respectively. Curves 1 through 6 correspond to the startup thermal profiles and Curve 7 corresponds to the steady state temperature distribution. The curves in Figure 7 for $s$ greater than $0.266 \mathrm{~m}$ and the complete curves in Figure 8 agree with the input temperatures shown in Figure 4. The inner surface temperatures shown in Figure 7 for $\mathrm{s}<0.266 \mathrm{~m}$ show only slight variations from the prescribed temperatures. This indicates that the temperature gradients through the thickness are small.

The meridional and circumferential stress distributions in the 316L SS receiver are shown in Figure 9 and Figure 10 for Steps 3 and 7, respectively. The meridional and the circumferential stress profiles are nearly equal. As a result, the effective von Mises stress are of similar magnitude to the individual components and are therefore not presented. The absorber shell is subjected to nearly pure bending with the inner surface of the shell in tension and the outer surface in compression. The stress magnitudes exceed $100 \mathrm{MPa}$. The bending response is due to the differential thermal expansion through the wall thickness caused by the temperature gradient. Large stress gradients occur near the junction of the absorber and aft dome due to the difference between the average temperatures of the absorber and aft dome and the geometric discontinuity which exists between the shell thicknesses at this location. The effective stress is very close to the $103 \mathrm{MPa}$ yield strength of $316 \mathrm{~L} \mathrm{SS}$. Membrane stresses in the receiver are characterized by an offset from zero in the average meridional and circumferential stress components. This membrane stress is tensile in the absorber and compressive in the aft dome.

At steady state operating conditions, the inner surface remains in tension, and the outer surface remains in compression with the maximum tensile and compressive stresses reduced to $42 \mathrm{MPa}$ and $-33 \mathrm{MPa}$, respectively. The meridional and circumferential stresses for the outer surface are almost identical and overlap in Figure 10. The stress profiles exhibit the distinctive double hump characteristic of the incident solar flux distribution shown in Figure 6. Near the absorber edge, the stress components are only $10 \mathrm{MPa}$ because the surface temperature of the receiver is more uniform during steady state operation. At steady state, the edge stress gradient is due primarily to the geometric discontinuity which exists at the absorber/aft dome interface.

\subsubsection{Haynes 230 Receiver}

The temperatures generated on the inner and outer surfaces of the Haynes 230 receiver were practically the same as those discussed for the $316 \mathrm{~L}$ SS receiver. As a result, they are not presented. The similarity was not surprising since the thermal properties of the two materials are so similar. The comments made regarding the temperature distribution for the $316 \mathrm{~L}$ SS receiver are still valid for this receiver material. 


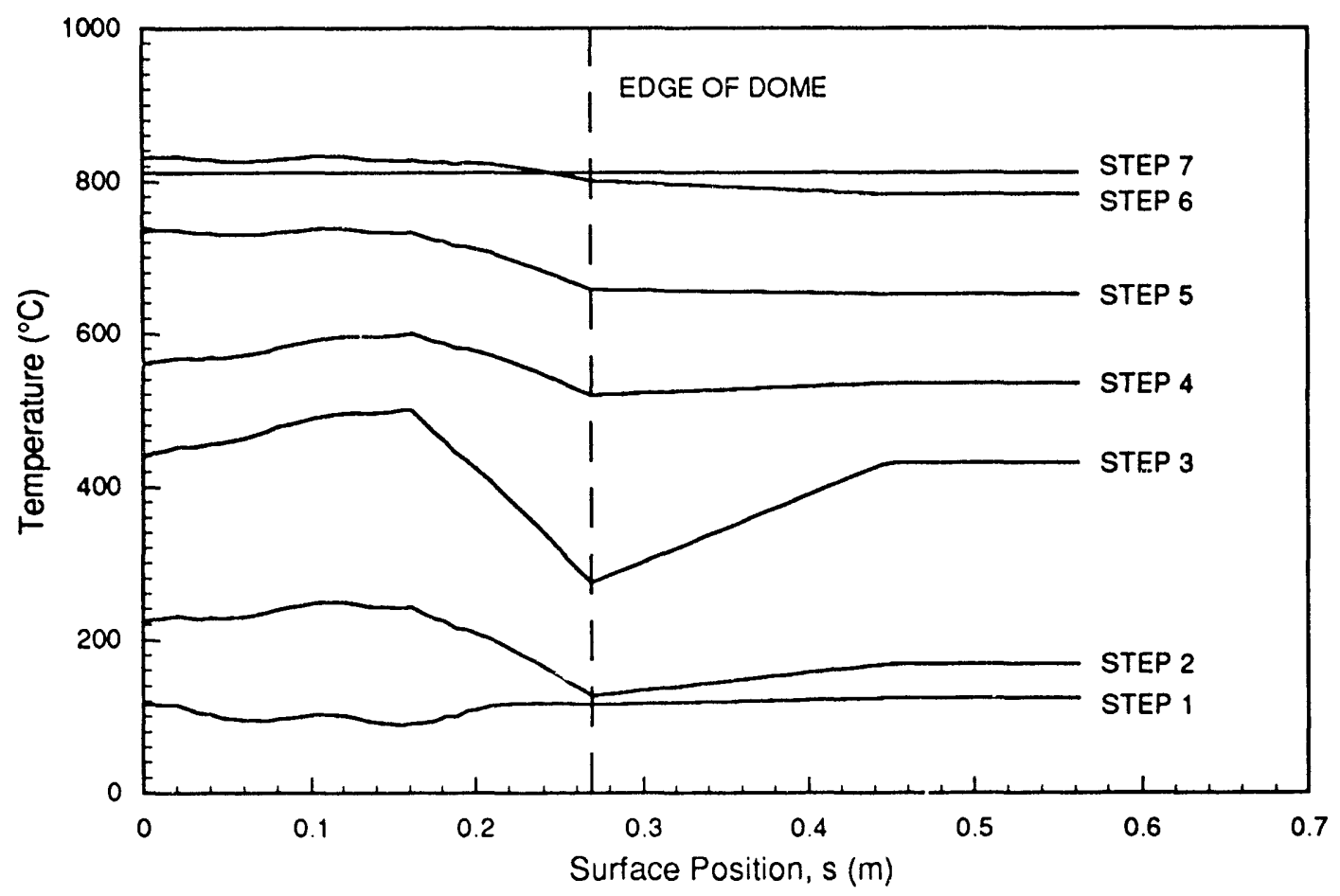

Figure 7. Absorber and aft dome inner temperature profiles for startup and steady state operating conditions.

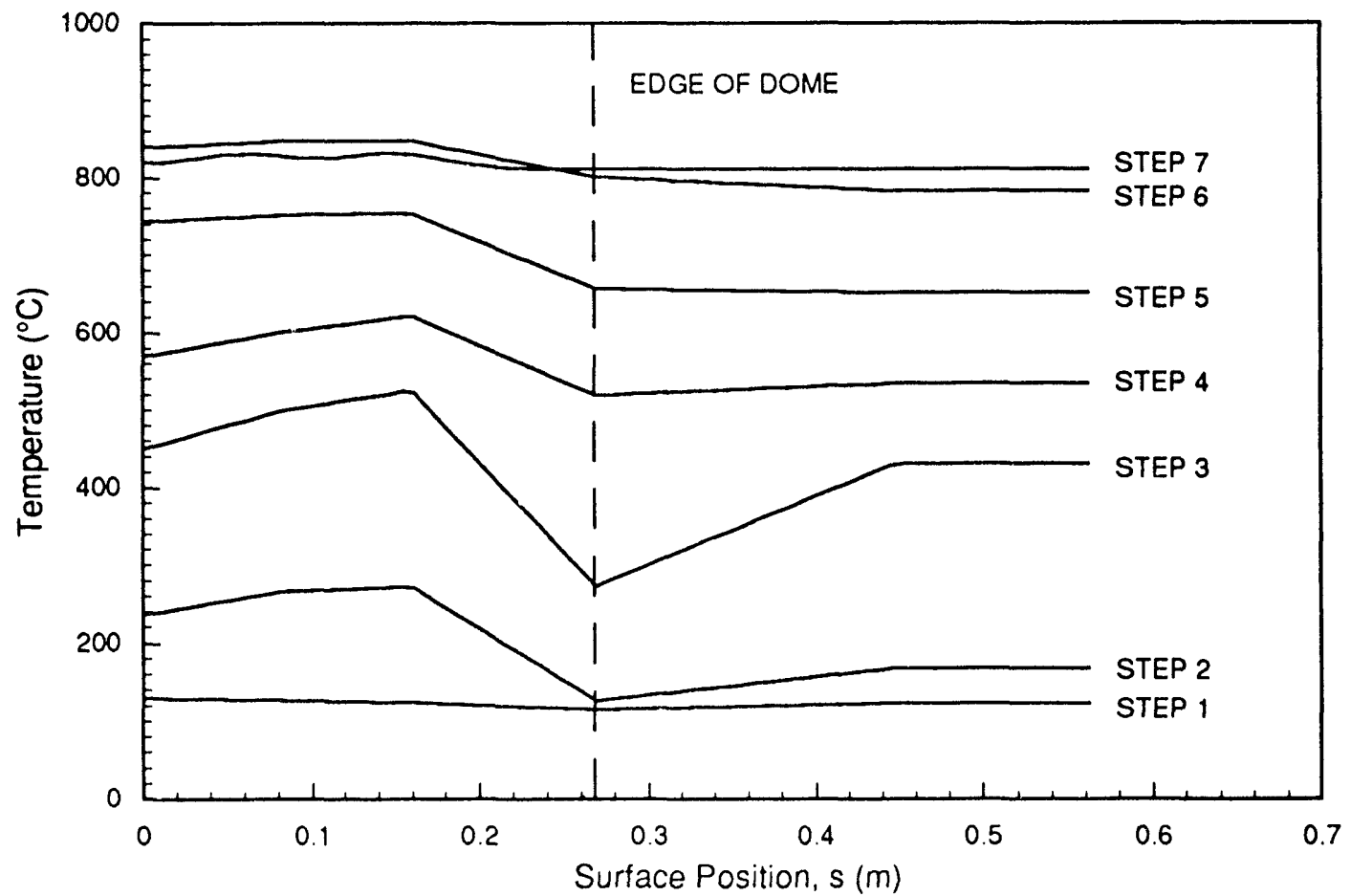

Figure 8. Absorber and aft dome outer temperature profiles for startup and steady state operating conditions. 


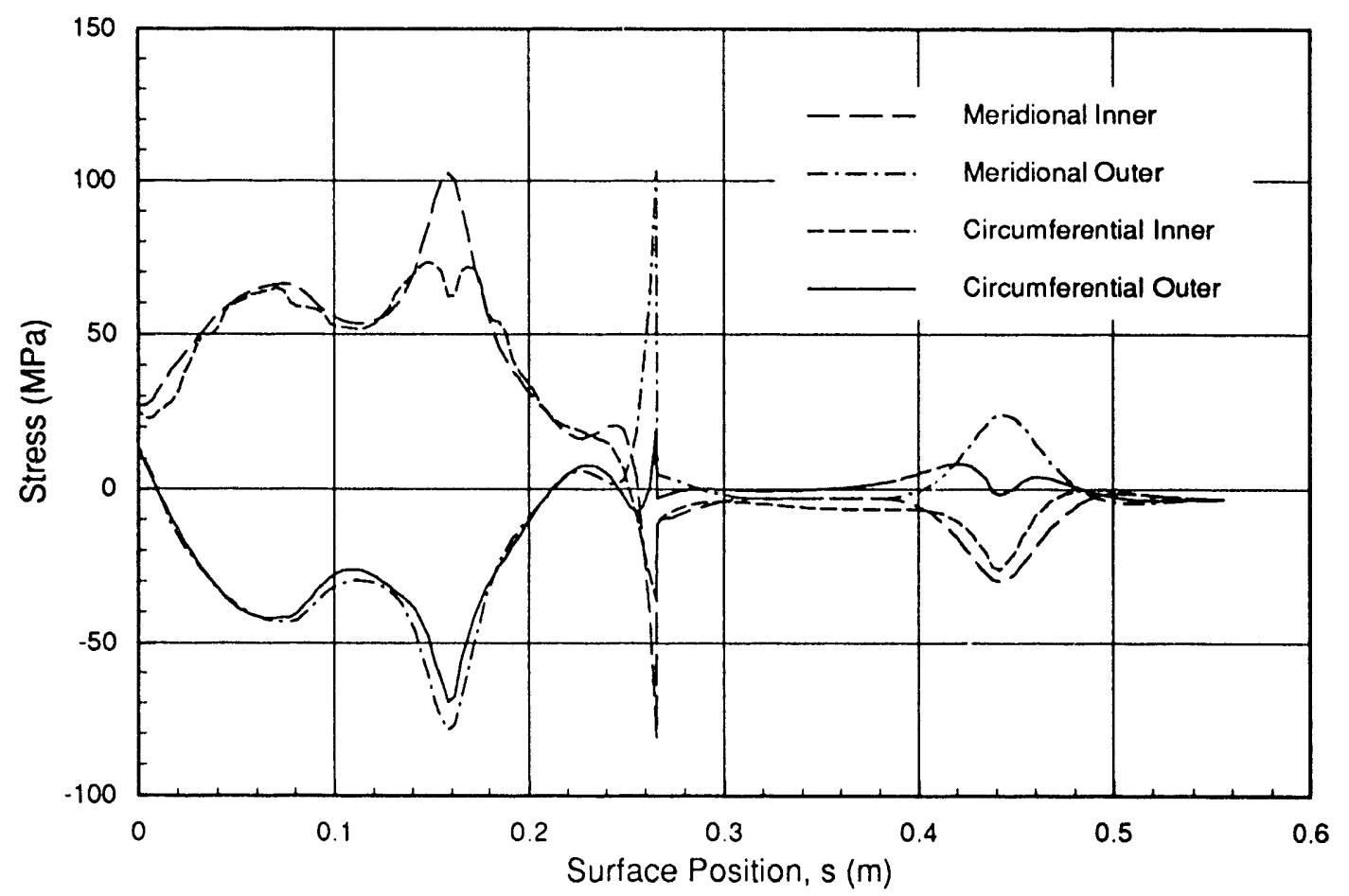

Figure 9. Receiver meridional and circumferential stress profiles during Step 3 of the receiver startup for $316 \mathrm{~L} \mathrm{SS}$.

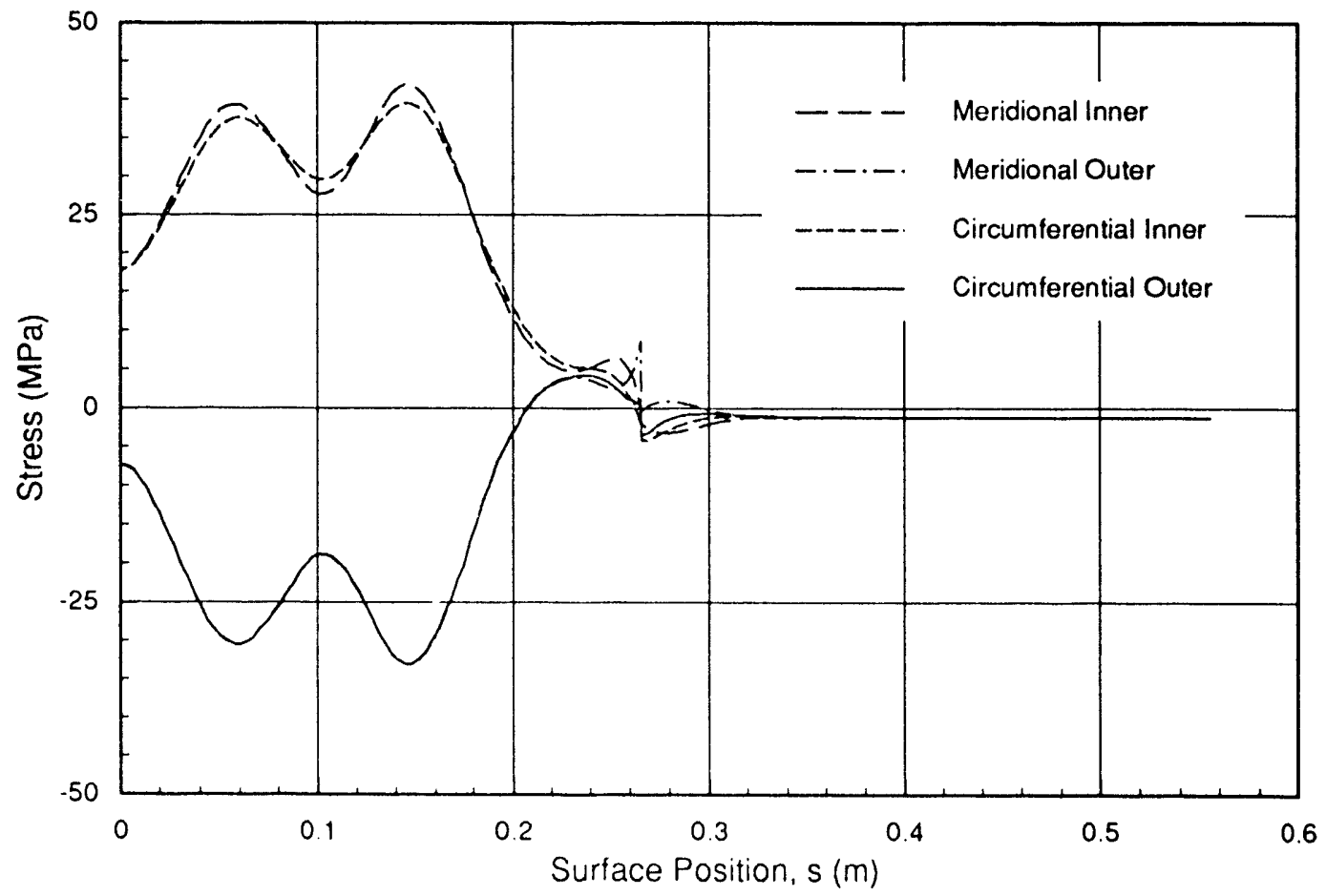

Figure 10. Receiver meridional and circumferential stress profiles during steady state operation (Step 7) for 316L SS. 
The meridional and circumferential stress profiles in the Haynes 230 receiver are shown in Figure 11 and Figure 12 for Steps 3 and 7, respectively. Again, the stress gradient through the shell thickness is caused by the thermal gradient and is characteristic of a pure bending load. The stresses on the inner surface are tensile and the stresses on the outer surface are compressive. As in the 316L SS receiver, large stress gradients occur near the weld location due to the difference between the average temperatures of the absorber and aft dome. During startup, the maximum tensile stress is near $100 \mathrm{MPa}$ while the maximum compressive stress is $-77 \mathrm{MPa}$. During steady state operation, the inner surface values reach a maximum of $45 \mathrm{MPa}$ and the outer surface stresses reach a maximum near $-35 \mathrm{MPa}$. The stress near the absorber edge reduced to $20 \mathrm{MPa}$ from a startup value of $90 \mathrm{MPa}$ because the surface temperature of the aft dome and absorber is uniform during steady state operation. The small stress gradient present during steady state operation is due primarily to the geometric discontinuity of the seam-weld and the different thicknesses of the absorber and aft dome. The stress profile contains the double hump shape characteristic of the incident solar flux distribution shown in Figure 6 . The maximum effective stress in the receiver is about 39 percent of the $260 \mathrm{MPa}$ yield strength of Haynes 230 at $800^{\circ} \mathrm{C}$.

\subsubsection{Conclusions on Material Selection}

The temperature distributions obtained for 316L SS and Haynes 230 are essentially the same due to their similar material properties. The stresses in the $316 \mathrm{~L} \mathrm{SS}$ receiver are near the yield strength $(103 \mathrm{MPa})$, while the higher yield strength of Haynes 230 results in maximum stresses about 39 percent of yield $(260 \mathrm{MPa})$. The maximum stresses in both materials are generated during startup due to the uneven temperature distribution across the receiver surface. It should be noted that the larger stresses at the weld location during startup might not represent the actual operating stress because of the low resolution of the temperature data and the linear interpolation scheme applied to them. The stress magnitude would be smaller if startup temperatures across the receiver surface were more uniform.

\subsection{Aft Dome Optimization}

In the preceding calculations, a large stress jump was observed at the seam-weld interface of the absorber and aft dome. This jump could be attributed to two factors: the uneven temperature distribution over the receiver and the geometric discontinuity of the shell thicknesses at this location. The latter cause could be eliminated by reducing the aft dome shell thickness to one closer to the absorber. However, this would also increase the membrane stresses on the aft dome since the stress area would be reduced. The following calculations investigate the effect of reducing the aft dome thickness on the overall stress state of the receiver.

The reduced aft dome calculations utilize the same model and boundary conditions used for material assessment. Subsequently, the temperature profiles in the receiver were identical to 


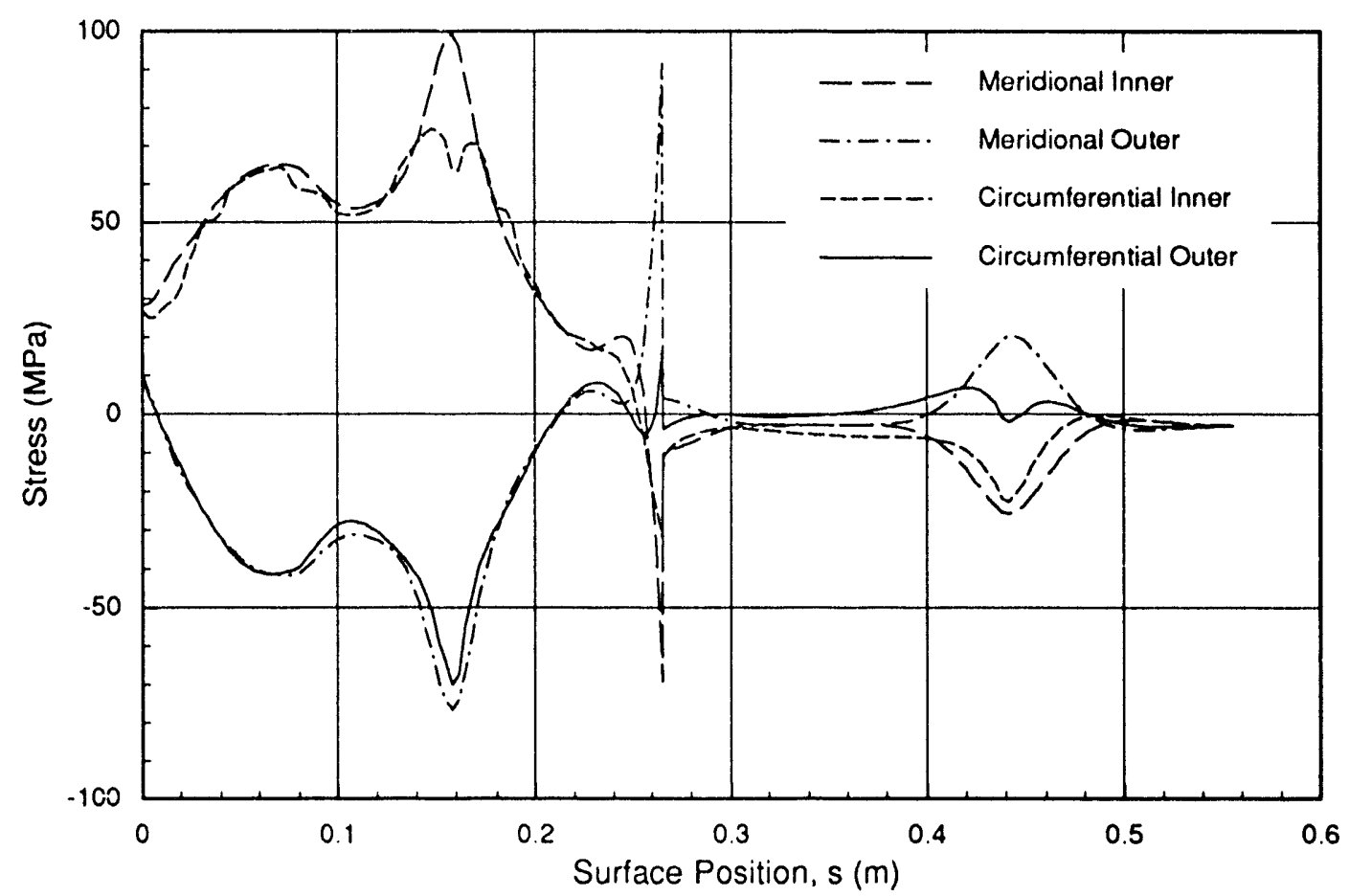

Figure 11. Receiver meridional and circumferential stress profiles during Step 3 of the receiver startup for Haynes 230.

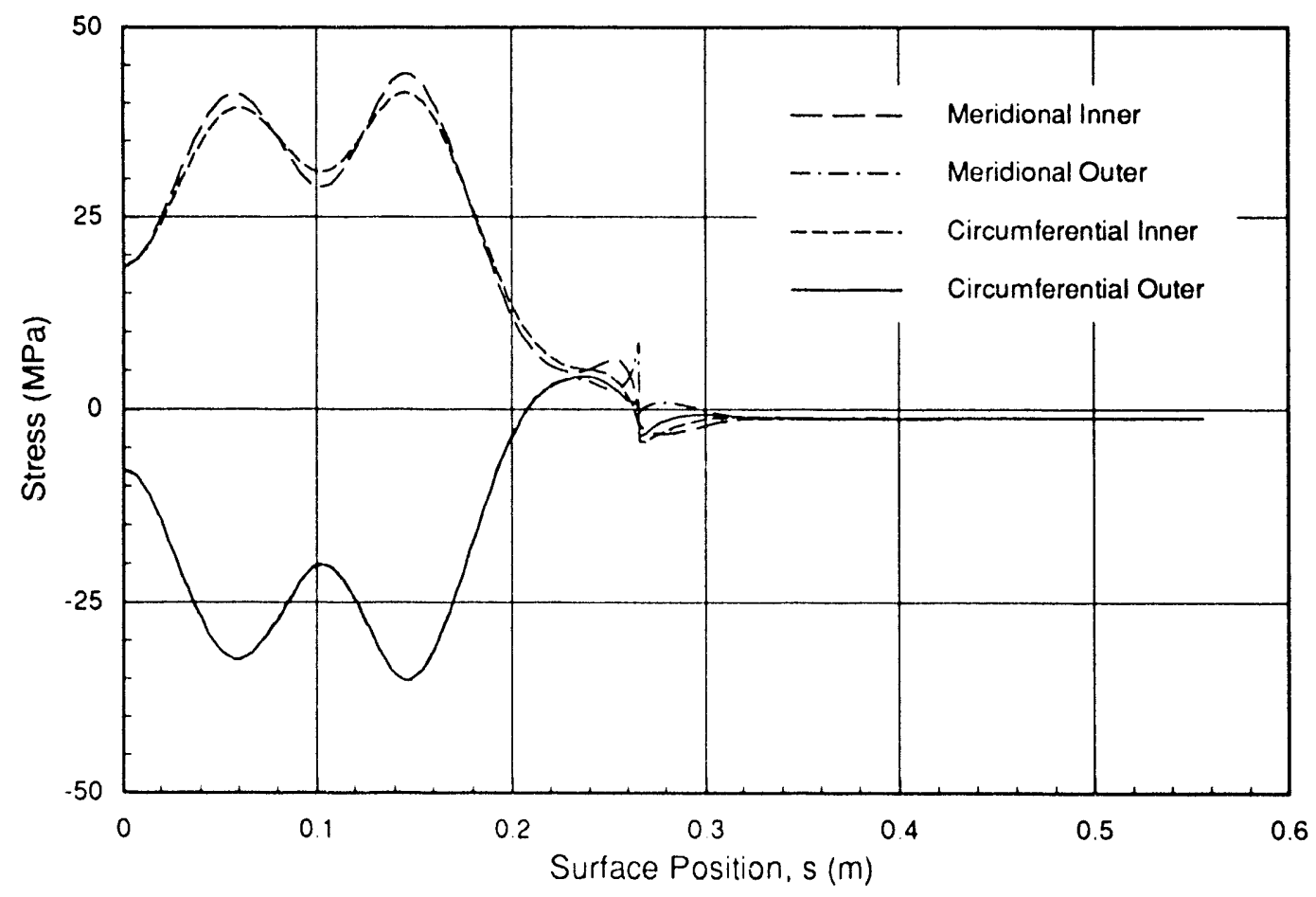

Figure 12. Receiver meridional and circumferential stress profiles during steady state operation (Step 7) for Haynes 230. 
those shown in Figure 7 and Figure 8. Since these calculations were performed for optimization of the next-generation receiver, only Haynes 230 properties were considered. The calculations were performed for half-thickness $(1.59 \mathrm{~mm})$ and quarter-thickness $(0.819 \mathrm{~mm}) \mathrm{aft}$ domes. Again, the stress distributions are presented for Steps 3 and 7 for each calculation.

\subsubsection{Half-Thickness Aft Dome}

The meridional and circumferential stress profiles in the Haynes 230 receiver with a $1.59 \mathrm{~mm}$ aft dome are shown in Figure 13 and Figure 14 for Steps 3 and 7, respectively. Comparing the startup stress profiles of the full-thickness (Figure 11) and half-thickness (Figure 13) receivers shows that the maximum stress in the inner surface of the absorber reduces from $100 \mathrm{MPa}$ for the full-thickness aft dome to $75 \mathrm{MPa}$ for the half-thickness aft dome. Similarly, the maximum stress in the outer surface of the absorber reduces from-75 MPa for the full-thickness aft dome to $-52 \mathrm{MPa}$ for the half-thickness aft dome. The maximum stresses in the aft dome are also reduced for the half-thickness aft dome. These stress reductions are offset by a larger compressive membrane stress in the aft dome. A comparison of the steady state stress profiles of the 'ull-thickness (Figure 12) and half-thickness (Figure 14) receivers shows that no significant changes occur. With the reduction in the aft dome thickness to $1.59 \mathrm{~mm}$, the maximum effective stress in the receiver is below 29 percent of the yield strength, compared to 39 percent for the $3.18 \mathrm{~mm}$ aft dome.

\subsubsection{Quarter-Thickness Aft Dome}

The previous section showed that the stress state in the Haynes 230 receiver was improved by reducing the aft dome thickness to $1.59 \mathrm{~mm}$. To determine if further stress reductions could be achieved, the Haynes 230 shell model was analyzed for equal absorber and aft dome thicknesses $(0.819 \mathrm{~mm})$. The meridional and circumferential stress profiles in the Haynes 230 receiver with a quarter-thickness aft dome are shown in Figure 15 and Figure 16 for Steps 3 and 7, respectively. Comparison of the startup stress profiles for the quarter-thickness (Figure 15) and half-thickness (Figure 13) aft domes shows that no appreciable changes occur with this additional reduction in aft dome thickness. The compressive membrane stress in the aft dome increased slightly. More significantly, the maximum stress near the weld reduced to 45 $\mathrm{MPa}$ from $75 \mathrm{MPa}$ for the $1.59 \mathrm{~mm}$-thick aft dome. This supports the original contention that the stress gradient near the seam-weld could to attributed to, among other things, the differential wall thickness of the absorber and aft dome. The steady state stress profiles (Figure 14 and Figure 16) show little change with further reductions in aft dome thickness. 


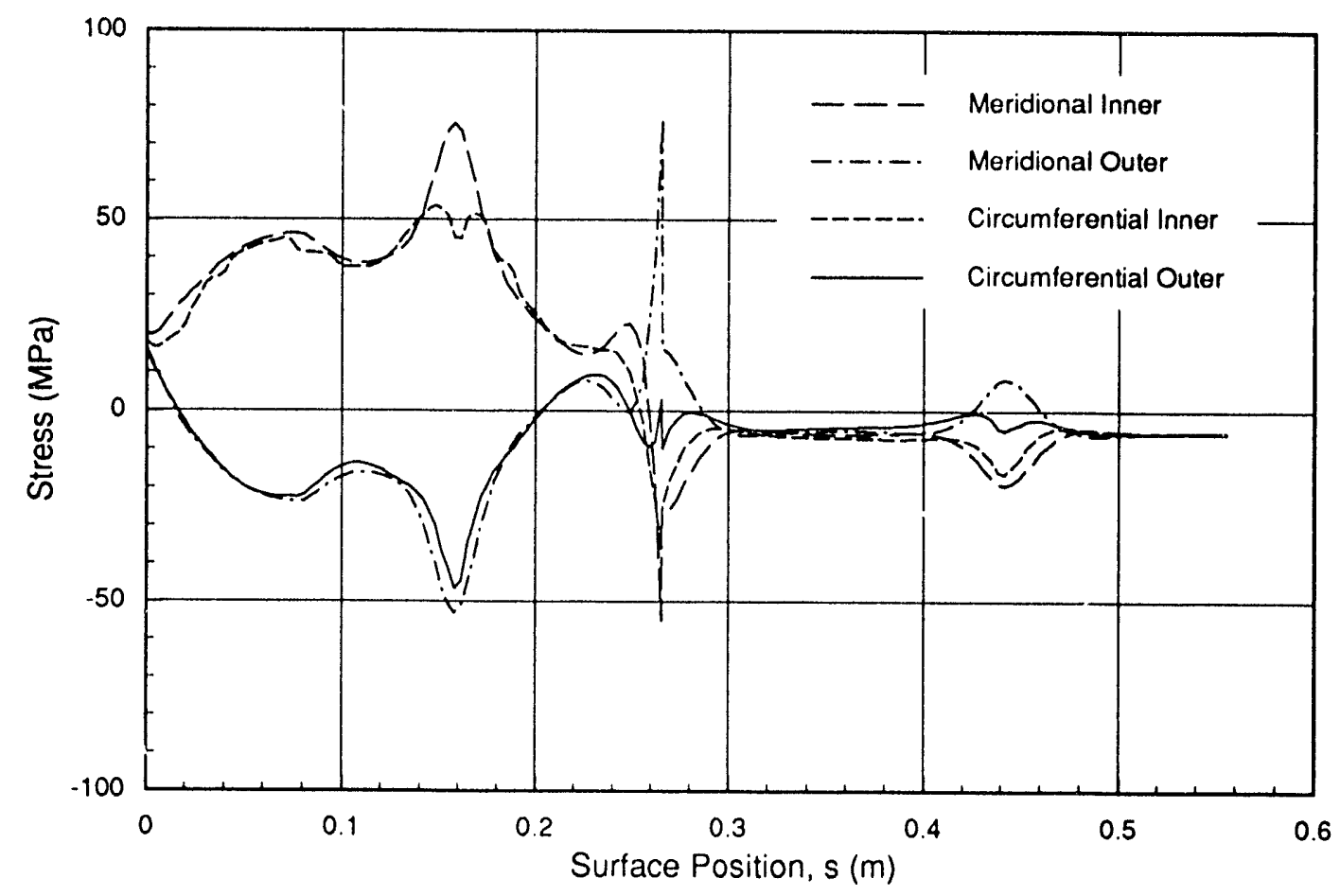

Figure 13. Receiver meridional and circumferential stress profiles during Step 3 of the receiver startup for Haynes 230 and a half-thickness $(1.59 \mathrm{~mm})$ aft dome.

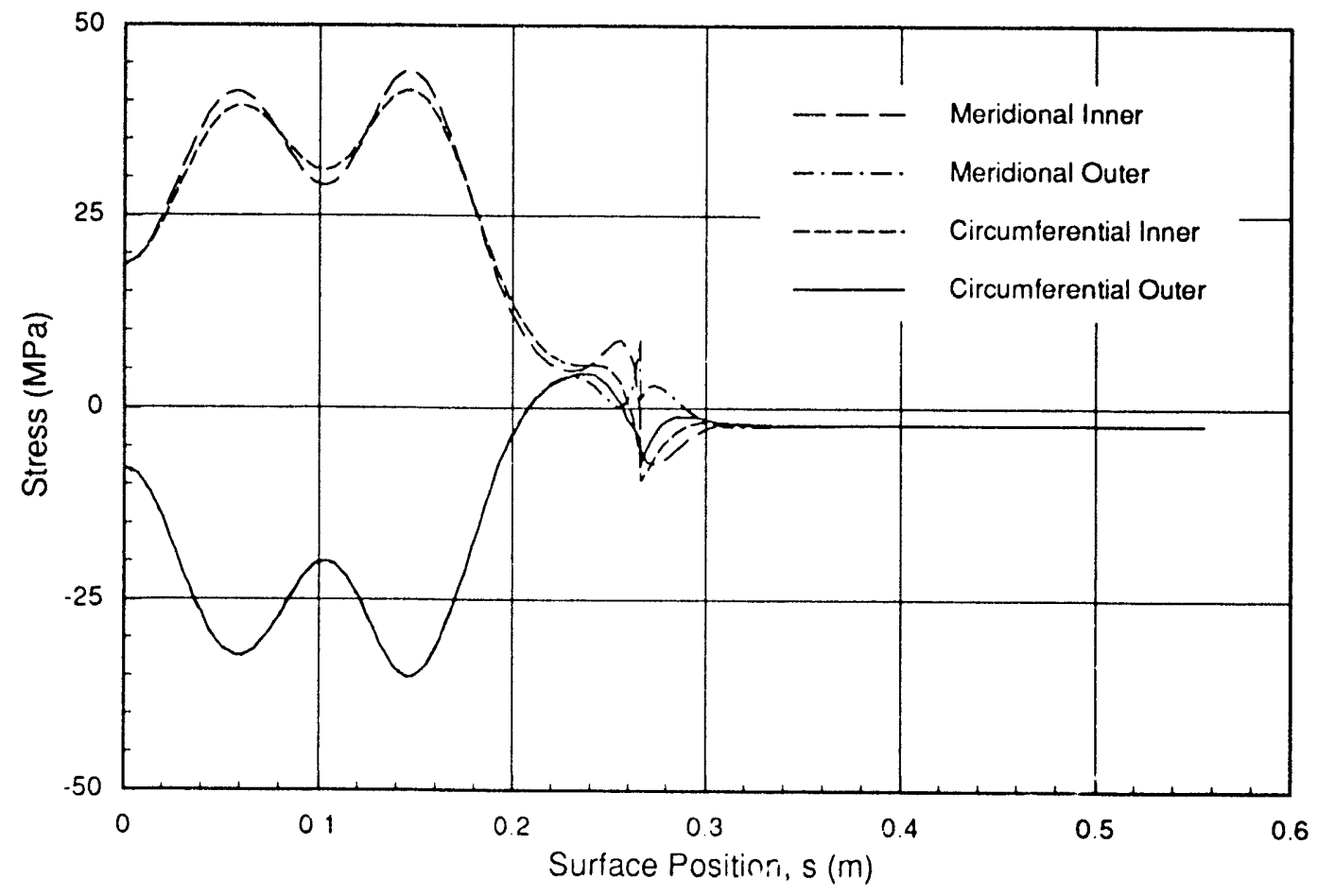

Figure 14. Receiver meridional and ciccumferential stress profiles during steady state (Step 7) operation for Haynes 230 and a half-thickness $(1.59 \mathrm{~mm}$ ) aft dome. 


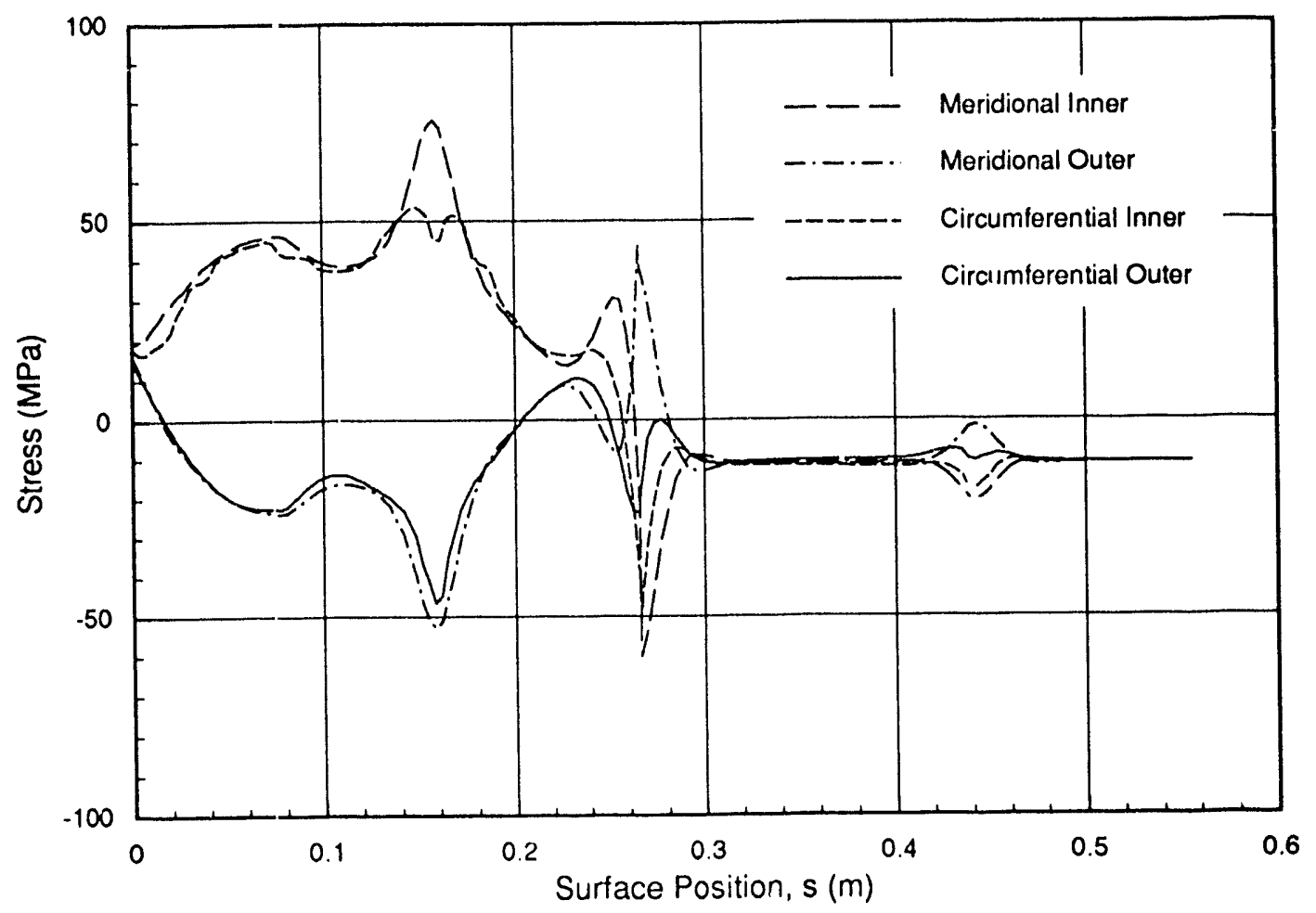

Figure 15. Receiver meridional and circumferential stress profiles during Step 3 of the receiver startup for Haynes 230 and a quarter-thickness $(0.813 \mathrm{~mm})$ aft dome.

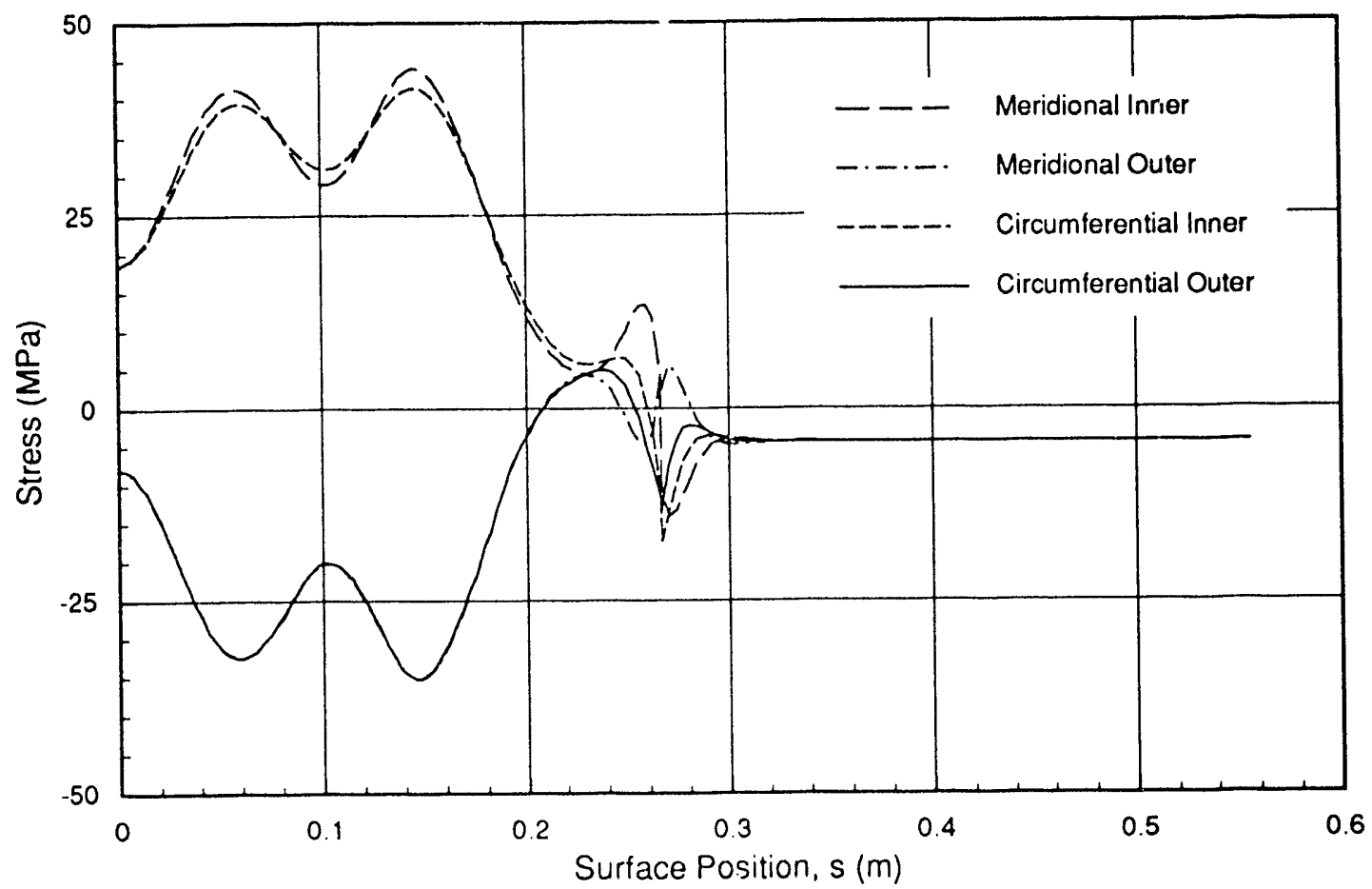

Figure 16. Receiver meridional and circumferential stress piofiles during steady state operation for Haynes 230 and a quarter-thickness $(0.813 \mathrm{~mm})$ aft dome. 


\subsubsection{Optimum Aft Dome Thickness}

The preceding calculations have demonstrated that a reduction in the aft dome thickness reduces the maximum absorber stresses during startup. Reducing the aft dome thickness from 3.18 to $1.59 \mathrm{~mm}$ resulted in a 25 percent decrease in absorber stress during startup. Although subsequent reductions in the aft dome thickness can further decrease absorber stress, there are diminishing returns as the absorber wall thickness is approached. The most significant benefit in reducing the aft dome thickness to $0.819 \mathrm{~mm}$ is a 40 percent reduction of the peak seamweld stress. As expected, due to a substantial reduction in the stress area, the compressive membrane stress in the aft dome increased with reductions in aft dorne thickness. Finally, reducing the aft dome thickness did not significantly affect the steady state stress profiles. It should be noted that these calculations do not consider the support load imposed on the aft dome by the 0.203 -m-diameter pipe. These loads could place a limit on the aft dome thickness. A three-dimensional analysis of the receiver would be required to investigate gravity loading. 


\section{Seam-Weld Fatigue Analyses}

As the development of a next-generation receiver progressed, the program focused on optimization and life issues. The proposed seam-weld crevice between absorber and aft dome was identified as a potential threat to the projected lifetime of the receiver [9]. Inspection of the inner surface stress distributions as calculated in the shell analyses (Figure 11 and Figure 12) shows that the inner surface of the weld is in compression during both startup and steady state phases of operation, in both the circumferential and meridional components. Because the shell analyses cannot capture the detail of the seam-weld, a more detailed analysis of the weld was performed and is presented in this section.

Treating the weld crevice as a crack (i.e. neglecting crack initiation time), the stress distribution near the seam-weld was investigated for constant amplitude load fluctuation between the unloaded (off-sun) condition and steady state (on-sun) thermal loading. The worst case start up condition (Step 3) was not considered for reasons which will be discussed later. Based on linear elastic fracture mechanics (LEFM) techniques [12], the fluctuation in the stress intensity factor near the crack tip was calculated for one load cycle. These calculations were performed using the J-integral method and crack opening-displacement field equations.

The following section describes the finite element model used to study the seam-weld. Next, the fracture parameters used in these calculations are defined and briefly explained. Finally, a description is given of the cyclic loads applied to the receiver. Calculations are presented for the elastic load cycling $b_{\text {-iween }}$ on-sun and off-sun conditions. Additional calculations are presented in which assumptions are made to approximate long-term creep effects. The results of the analyses are given for the various load cases representing the amplitude of the applied loads. These calculations are used in conjunction with fatigue data to determine whether a fracture will propagate through the seam-weld.

\subsection{Finite Element Model}

A cross section of a candidate seam-weld between the absorber and aft dome is shown in Figure 17. All of the candidates under consideration have in common the built-in "crack" that is evident in this photograph. To capture the detail of the seam-weld, a mesh was needed with more detail than the shell model used in the previous analyses. The finite element mesh of the reflux pool-boiler receiver is shown in Figure 18. The model consists of 1757 axisymmetric continuum elements and 6986 nodes. The elements are 8-node quadrilaterals written for fully coupled temperature-displacement analysis. These elements use biquadratic displacement interpolation and bilinear temperature interpolation. Because the elements are higher order in displacement and the stresses are linear, only two elements were used through the thickness of the absorber and aft dome at locations away from the seam-weld. As is recommended in fracture mechanics analysis, the mesh is focused at the tips of the weld notches. In addition, the mid-side nodes of the elements closest to the notch tip are moved to the $1 / 4$-point positions next to the crack tip 


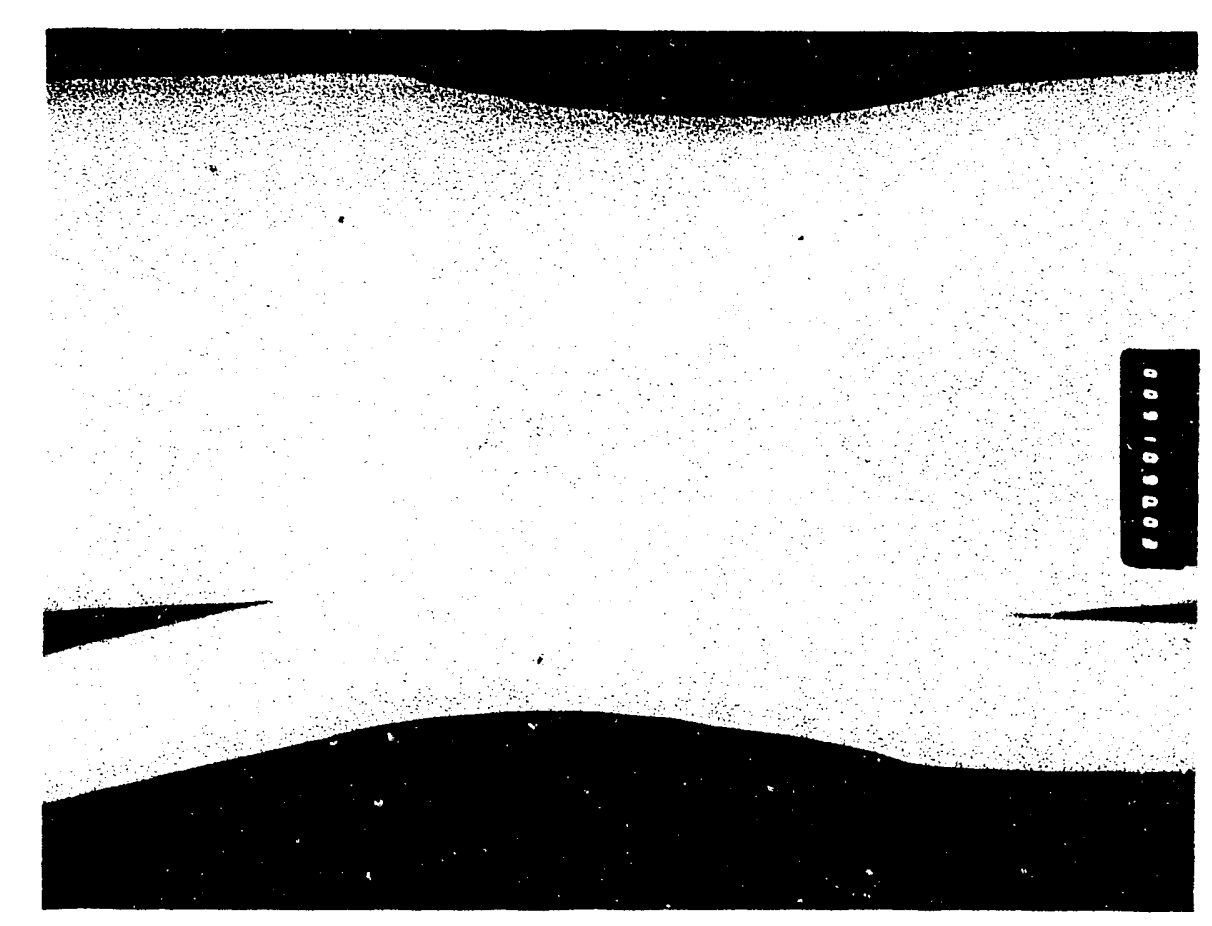

Figure 17. Cross section of a candidate seam-weld joining the absorber and aft dome of the reflux pool-boiler receiver.

as illustrated in Figure 19. Coincident nodes at the crack tip are constrained to have the same displacements. These adjustments produce a $r^{-1 / 2}$ strain singularity near the notch, where $r$ is the radial distance from the notch tip. Based on the previous shell element calculations, the upper notch was expected to be subjected to a slightly harsher stress environment at steady state operating conditions than the lower notch. However, both notch meshes were concentrated so that the stress intensification could be investigated at each side of the weld.

\subsection{Definition of Fatigue Crack Growth Parameters}

Linear elastic fracture mechanics (LEFM) relates the stress magnitude and distribution in the vicinity of a crack tip to the nominal stress in the vicinity of the crack; the size, shape and orientation of the crack; and the material properties [12]. The magnitude of the elastic-stress field for opening mode displacement (Mode I) can be described by a single parameter, $\mathrm{K}_{\mathrm{I}}$, designated the stress intensity factor. Unstable fracture may occur when the stress intensity at the crack tip $\left(\mathrm{K}_{\mathrm{I}}\right)$ reaches the critical stress intensity factor, $\mathrm{K}_{\mathrm{c}}$. The critical stress intensity factcr represents the ability of a material to withstand a given crack tip stress intensity and resist progressive crack extension.

The stress intensity factor is related to the nominal stress $\sigma$ and flaw size $a$ for a given material as follows: 


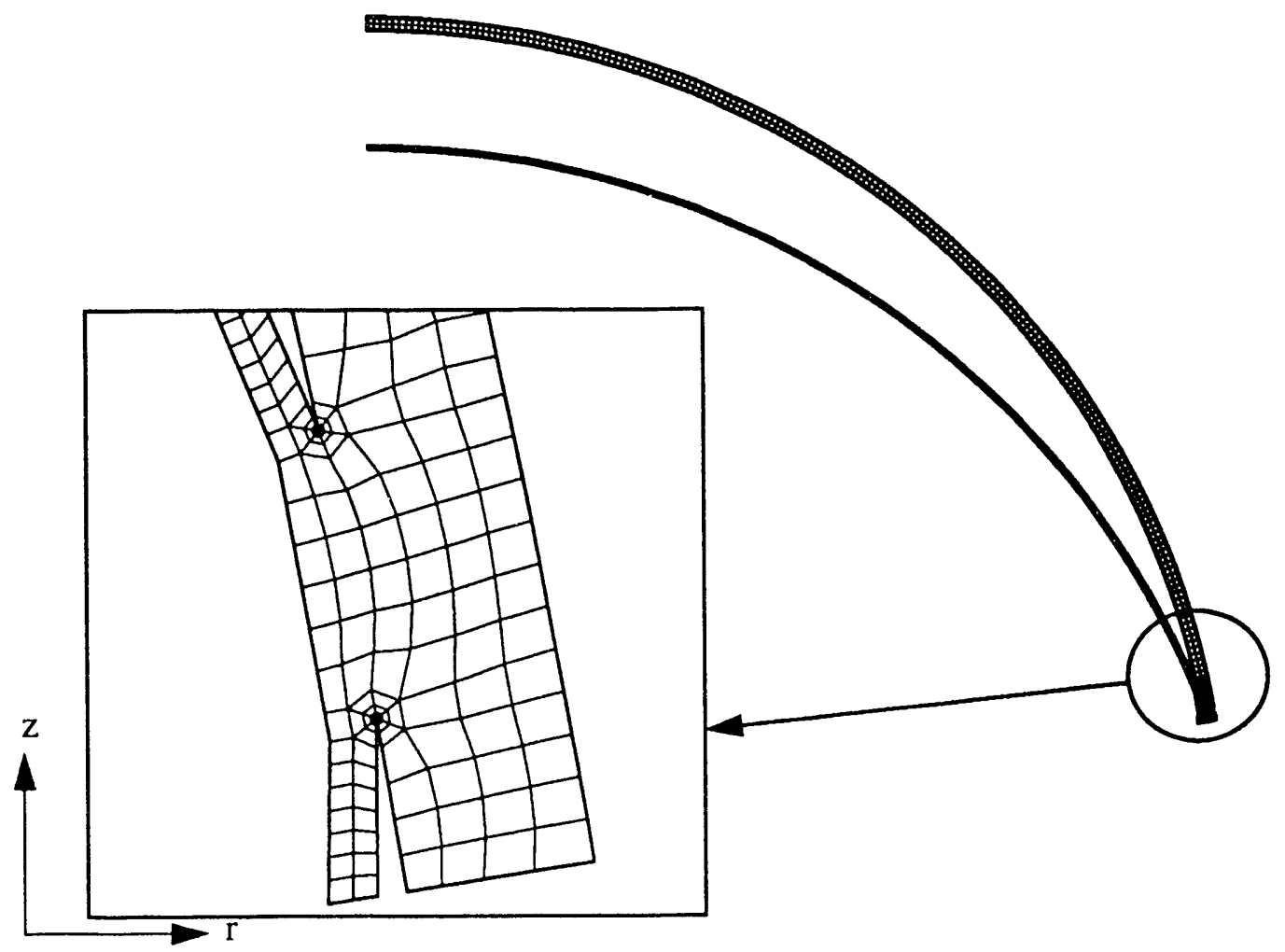

Figure 18. Finite element mesh of the reflux pool-boiler receiver.

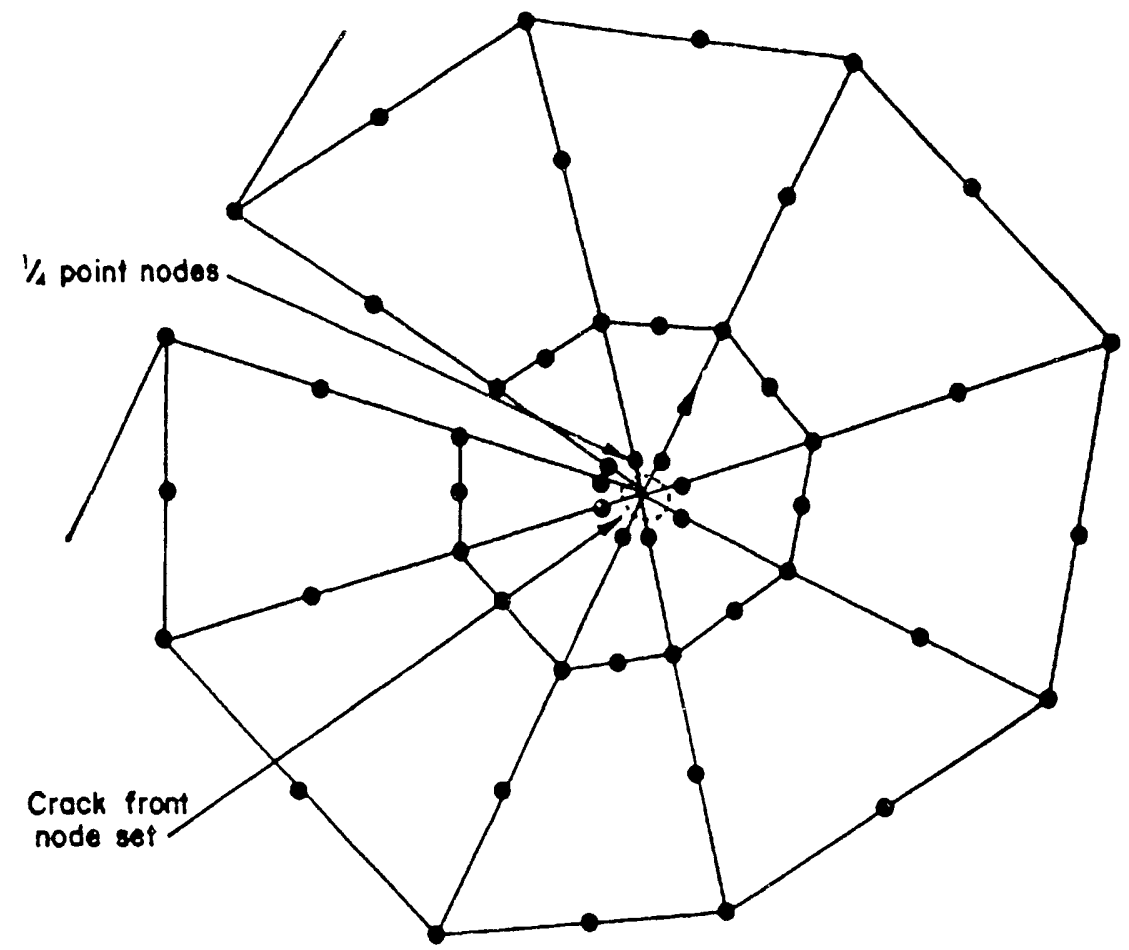

Figure 19. Focused mesh used at seam-weld notches [7]. 


$$
\mathrm{K}_{\mathrm{I}}=C \sigma \sqrt{a}
$$

where the constant $C$ is a function of the crack geometry. If a particular combination of crack size and stress in a structure $\left(\mathrm{K}_{\mathrm{I}}\right)$ reaches the $\mathrm{K}_{\mathrm{c}}$ level, fracture can occur.

Subcritical or fatigue crack growth may also occur where the load conditions are such that the stress intensity factor $\mathrm{K}_{1}$ is significantly less than $\mathrm{K}_{\mathrm{c}}$. Under constant amplitude load fluctuation, the subcritical crack growth rate can be estimated from a knowledge of the fluctuation of the stress intensity factor, $\Delta \mathrm{K}_{\mathrm{I}}$. The most common presentation of crack growth data is a log$\log$ plot of the crack growth per cycle, $\mathrm{d} a / \mathrm{dN}$, versus the fluctuation of the stress intensity factor, $\Delta \mathrm{K}_{\mathrm{I}}$. Figure 20 illustrates the form of typical fatigue-crack growth data. The propagation behavior for metals can be divided into three regions. In Region I the data is characterized by near-threshold behavior. In this region, a small decrease in the stress intensity factor results in a large decrease in the crack growth rate $(\mathrm{d} a / \mathrm{dN})$. Below this "fatigue-threshold" cyclic stress intensity factor, $\Delta \mathrm{K}_{\mathrm{th}}$, a crack will not propagate under cyclic stress. For most steels, this threshold is approximately $6 \mathrm{MNm}^{-3 / 2}(5.5 \mathrm{ksi} \sqrt{\mathrm{in}})$ [12]. In Region II the data exhibits fatiguecrack propagation behavior which can be mathematically modeled as

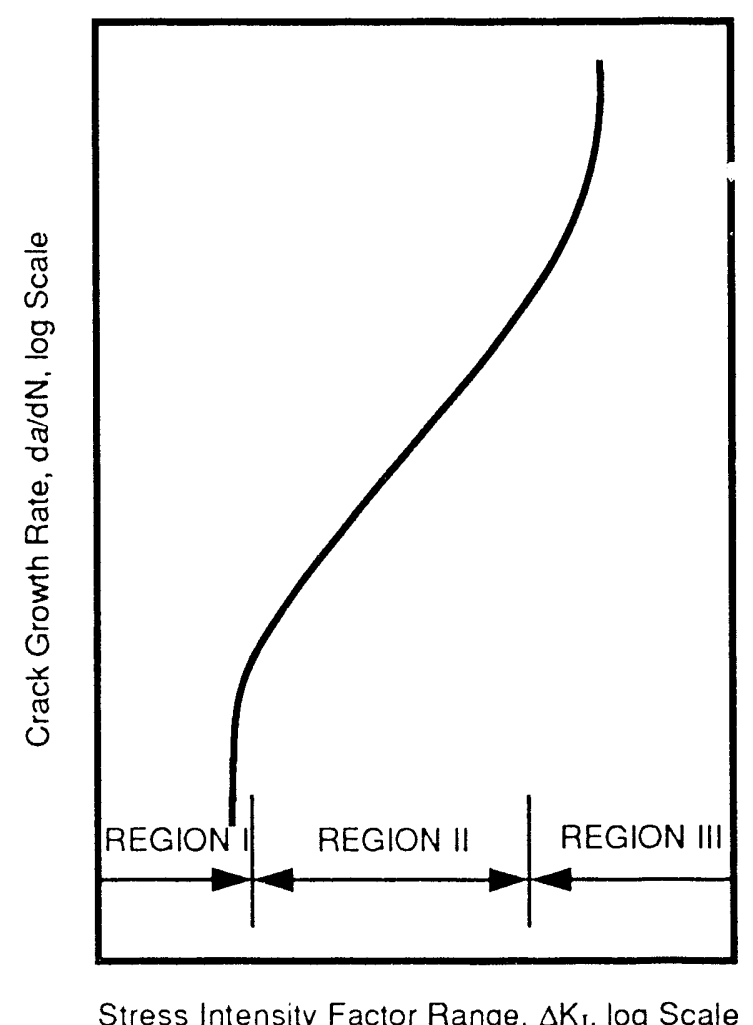

Figure 20. Schematic representation of fatigue-crack growth data [12] 


$$
\frac{\mathrm{d} a}{\mathrm{dN}}=A\left(\Delta \mathrm{K}_{\mathrm{I}}\right)^{\mathrm{n}}
$$

where $A$ and $\mathrm{n}$ are constants. In Region III the fatigue crack growth rate increases rapidly with small changes in $\Delta \mathrm{K}_{\mathrm{I}}$.

In the present calculations, the stress intensity factor is calculated using the J-integral method and crack opening-displacement field equations. Both methods are based on either plane strain or plane stress assumptions. For the following axisymmetric analyses, the plane strain assumption was used because the corresponding equations yield a conservative approximation of the stress intensity factor. A review of the two methods used to calculate the stress intensity factor is presented next. More information on the subject can be found in references $[12,13,14]$.

\subsubsection{J-Int $\because g r a l$}

The J-integral is a path-independent line integral about the crack tip which is a measure of the stress-strain field ahead of the crack. The line integral, J, is defined for either elastic or elasticplastic behavior as follows:

$$
J=\int_{R} W d x_{2}-T\left(\frac{\partial u}{\partial x_{1}}\right) d s
$$

where $R$ is any contour surrounding the crack tip as shown in Figure 21, $W$ is the strain energy density $\int_{0}^{\varepsilon} \sigma d \varepsilon, T$ is the traction vector defined according to the outward normal $n$ along $R, u$ is the displacement vector, and $d s$ is the arc !ength along contour $R$. The J-integral may be interpreted for elastic materials as the rate of change in potential energy between two identically

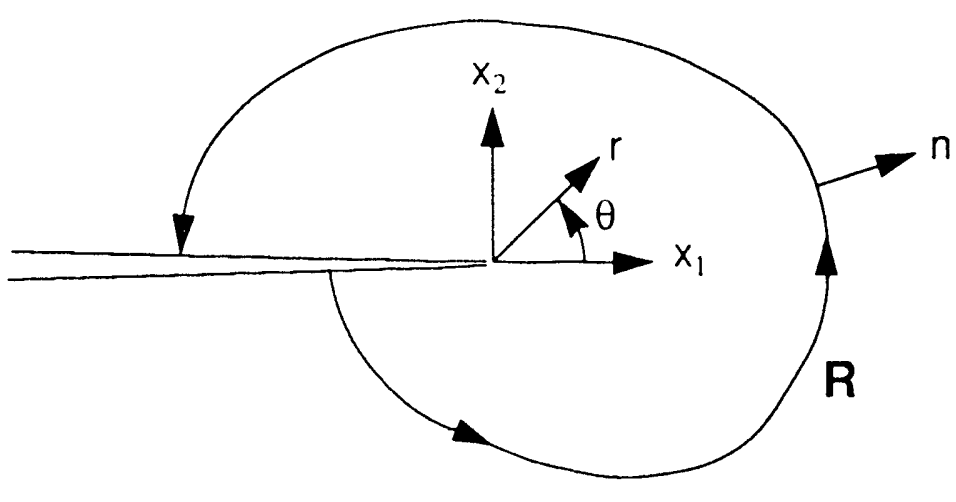

Figure 21. Crack-tip region, coordinate system and path independent J-integral. 
loaded bodies having slightly different crack lengths. For elastic plane strain conditions, the stress intensity factor is related to the J-integral parameter as follows:

$$
K_{1}=\sqrt{\frac{J_{1} E}{\left(1-v^{2}\right)}}
$$

\begin{abstract}
ABAQUS contains a procedure for calculating the $\mathrm{J}$-integral based on the method of virtual crack extension [14]. The evaluation of the line integral may be thought of as a contour line passing through a ring of elements surrounding the crack front. The evaluation can be performed for a number of such rings of elements. Since the integral is path independent, these values should be the same. For the particular mesh used in the present calculations, a J-integral calculation is performed for each of the three rings surrounding each crack tip (see Figure 18). Thermally loaded problems present a difficulty since the potential used in the formulation of the $\mathrm{J}$-integral procedure is structural only. This problem is addressed in Section 4.2.3.
\end{abstract}

\title{
4.2.2 Crack Opening-Displacement Equations
}

The crack opening-displacement field equations describe the stress and displacement fields in the vicinity of a crack in terms of the stress intensity factor, $\mathrm{K}_{\mathrm{I}}$, and other material properties. The Mode I displacement field equations are:

$$
\left(\begin{array}{l}
u_{1} \\
u_{2}
\end{array}\right)=\frac{K_{\mathrm{I}}}{2 \mu}\left(\frac{\mathrm{r}}{2 \pi}\right)^{1 / 2}\left(\begin{array}{l}
\cos (\theta / 2)\left[\kappa-1+2 \sin ^{2}(\theta / 2)\right] \\
\sin (\theta / 2)\left[\kappa-1+2 \cos ^{2}(\theta / 2)\right]
\end{array}\right)
$$

where $\mu$ is the shear modulus, $r$ is the radial distance from the crack, and $\theta$ is the orientation of the point as shown in Figure 21 . For plane strain conditions $\kappa=3-4 v$. These equations can be found in any fracture mechanics text $[12,13]$. In the present calculations, the stress intensity factor was calculated from the nodal displacements for the nodes along the interior surface of the weld notch $\left(\theta=180^{\circ}\right)$. For this case, $u_{1}=0$ and $u_{2}$ reduces to

$$
u_{2}=\frac{K_{I}}{2 \mu}\left(\frac{r}{2 \pi}\right)^{1 / 2}(\kappa-1)
$$

Using the finite element analysis results, the opening mode displacements $\left(u_{2}\right)$ for the first six nodes on each side of the nutch were calculated relative to the displacement of the crack tip. Using Equation (7), the stress intensity factor of the weld notch was calculated from the relative displacements. As in the case of the J-integral method, the equations which describe the displacement field at a crack tip consider structural loading only. 


\subsubsection{Application to Thermally Loaded Problems}

Because typical methods of calculating $\mathrm{K}_{\mathrm{I}}$ do not include thermal loads in their formulation, they cannot be blindly applied to coupled thermal-structural analyses. For thermal problems, ABAQUS recommends that very small elements be used near the crack tip such that the thermal load is treated simply as a body force [14]. This method was used for the coupled thermaldisplacement analyses of the reflux pool-boiler receiver. In addition, calculations were performed with only the structural loads applied. The results were compared to the thermally loaded problems to investigate the effects of thermal strains on the local stresses at the crack tip.

\subsection{Cyclic Load Environment}

The reflux pool-boiler receiver is subjected to constant amplitude load fluctuation between offsun and on-sun conditions. Early in the life of the receiver, the on-sun loads result from the thermal and structural loads at steady state operating conditions, and the off-sun loads are due only to the vacuum that exists in the receiver. After a long period of operation, the on-sun deviatoric stresses will relax due to high-temperature creep. When the receiver is cooled to offsun temperatures, a residual stress state will exist in the receiver. In this study, the off-sun residual stresses are approximated by reversing the thermal loads on the receiver. This was accomplished by simply reversing the sign of the coefficient of thermal expansion.

The reversed thermal load approximation assumes the receiver is stress-free when on-sun. This assumes the initial on-sun stresses have no volumetric component, because only deviatoric stresses produce creep. Since the meridional and circumferential components are nearly equal and the radial component is zero, there is a nonzero volumetric stress component. As a result, the on-sun stresses will not relax to zero and the reversed thermal load approximation yields conservative results.

Four load cases were analyzed using the reflux pool-boiler receiver model: (1) on-sun structural loading (Equation 1 for on-sun temperatures) with thermal loading (flux), (2) on-sun structural loading with no thermal loads, (3) off-sun structural loading (Equation 1 for off-sun temperatures) with reversed on-sun thermal loads, and (4) off-sun structural loading with no thermal loads. The first case represents the steady state operating conditions of the on-sun receiver. The third case, as previously stated, represents an approximation of the off-sun residual stress state when the receiver is held at on-sun temperatures for a long period of time and is then cooled to room temperature. The calculations with no thermal load were performed to determine the contribution of thermal strains to the stress state near the crack tip.

The fracture parameters calculated for the above four cases were used to calculate $\Delta \mathrm{K}_{\mathrm{I}}$ for the two cyclic load environments: (1) at early receiver life, and (2) after relaxation of on-sun stresses. Early in the receiver life, the stress fluctuation at the notch tip results from load cycling between thermal loading (Case 1) and off-sun loads due to internal pressure (Case 4). For the 
stress relaxation approximation, the stress fluctuation results from cycling between the reversed thermal loading (Case 3 ) and the on-sun "stress-free" condition.

\subsection{Analysis Results for Steady State Operation}

In the following sections the results of the four load cases are presented. First, the stress distributions near the weld crevice are investigated. The results of the calculations are presented in terms of the largest principal stress in the vicinity of the upper seam-weld notch since it is exposed to the harshest stress environment of the two weld notches. Post-processing of the calculations was performed using BLOT [15] which displays an 8-node quadrilateral as four 4node quadrilaterals. Consequently, plots of the results appear to have greater mesh refinement than the model shown in Figure 18. In the last sut ection, the results from the fracture parameter calculations are presented.

\subsubsection{Case 1: On-Sun Structural and Thermal Loading}

For verification of the finite element model, the results of this load case were compared to the results of the corresponding analysis performed using shell elements. The nodal temperatures computed along the outer surface of the absorber are shown in Figure 22 compared to the shell calculations. The temperatures from the two analyses are essentially identical. The stress output variable which is common to both analyses is the circumferential stress. Figure 23 compares the circumferential stress in the outer and inner surfaces of the absorber for both analyses. As in the shell calculations, the results show a stress gradient in the absorber wall which is caused by the thermal gradient through the wall. This stress distribution is characteristic of pure bending, with tensile stresses on the inner surface and compressive stresses on the outer surface. The results for the 8-node quadrilateral calculations are lower then the shell calculations because the stresses in the 8-node quadrilaterals are evaluated at the quadrature points of the elements, not at the surface. Hand calculations, extrapolating the temperature to the surface, verify that the analysis results agree.

Figure 24 is a plot of the largest principal stress distribution near the upper weld notch. The white region at the tip of the notch represents stresses beyond the range of the contour plot. The plot shows that a compressive stress field exists in front of the notch. A compressive stress field is not conducive to crack propagation. Furthermore, the magnitude of the stress is low, with maximum compressive stresses near $12 \mathrm{MPa}(1.74 \mathrm{ksi})$.

It is interesting to compare the continuum element results with the previous shell calculations under the same steady state load conditions. Note that the circumferential and meridional stress components in the corresponding shell analyses (Figure 12) are on the order of $7 \mathrm{MPa}$ on the inner surface near the seam weld. This compares well with the results presented in this section. 


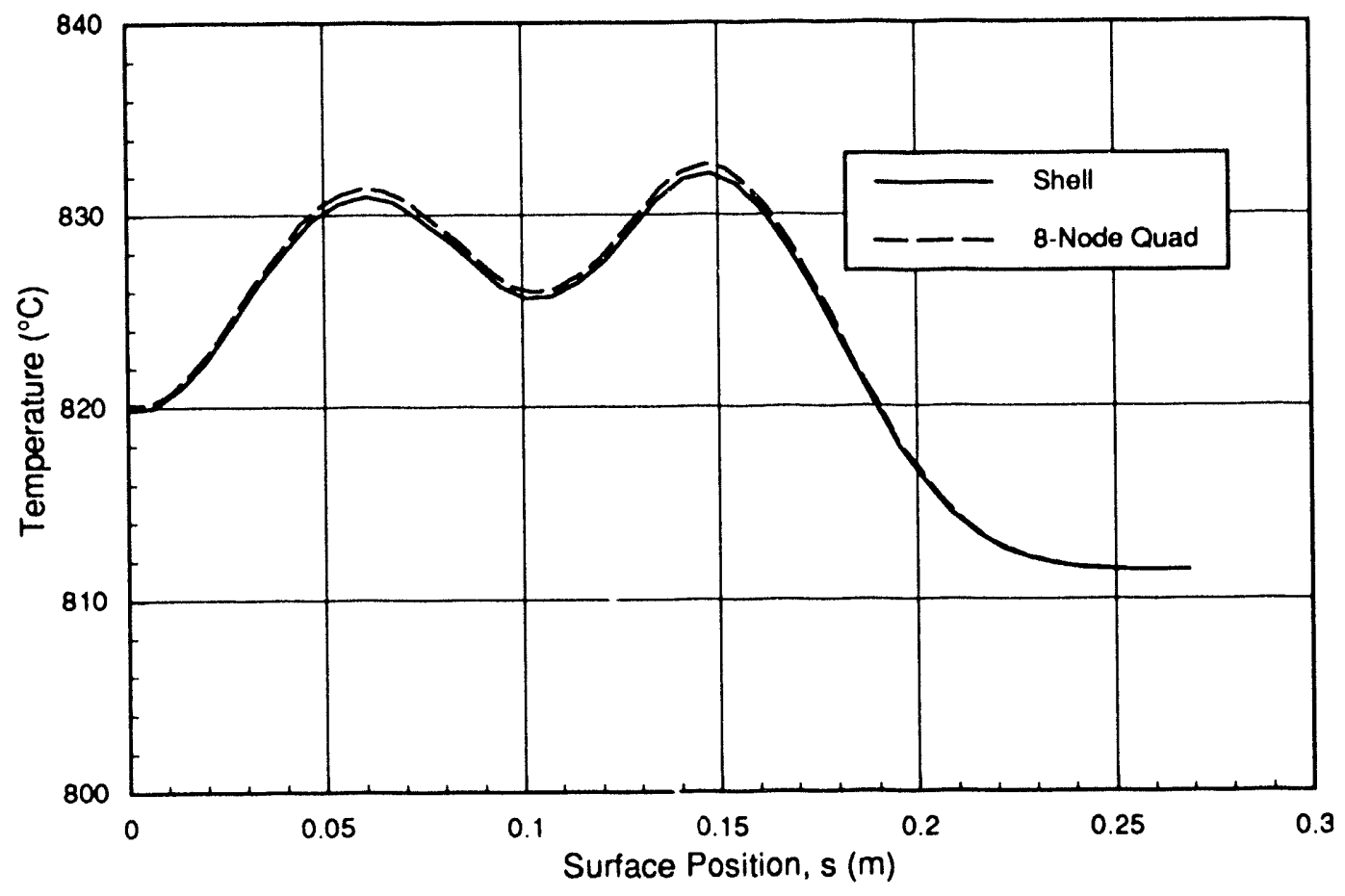

Figure 22. Temperature at the outer surface of the absorber calculated using axisymmetric shell elements and 8-node axisymmetric solid elements for on-sun structural and thermal loading (Case 1).

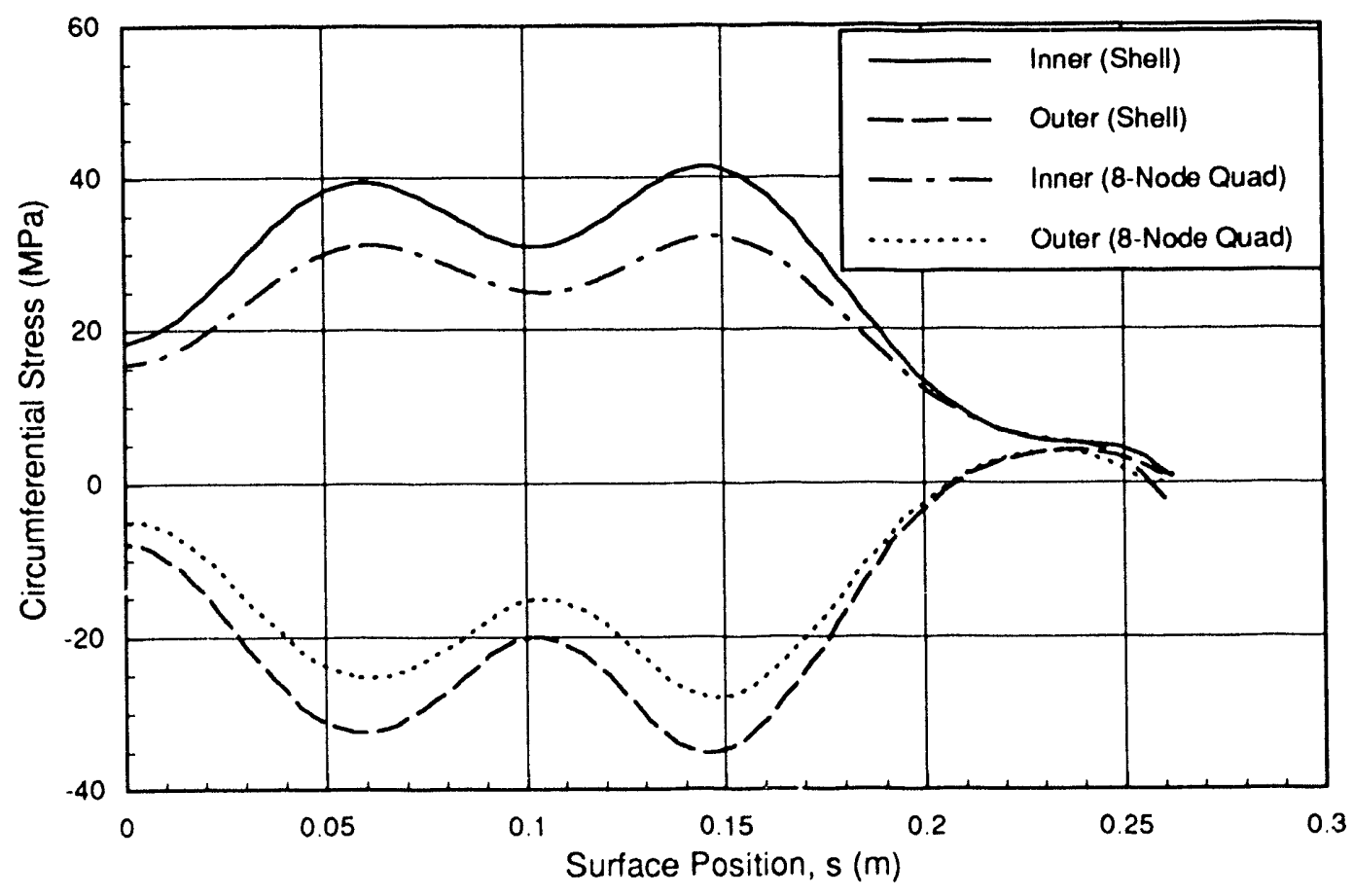

Figure 23. Circumferential stress in absorber calculated using axisymmetric shell elements and 8-node axisymmetric solid elements for on-sun structural and thermal loading (Case 1). 

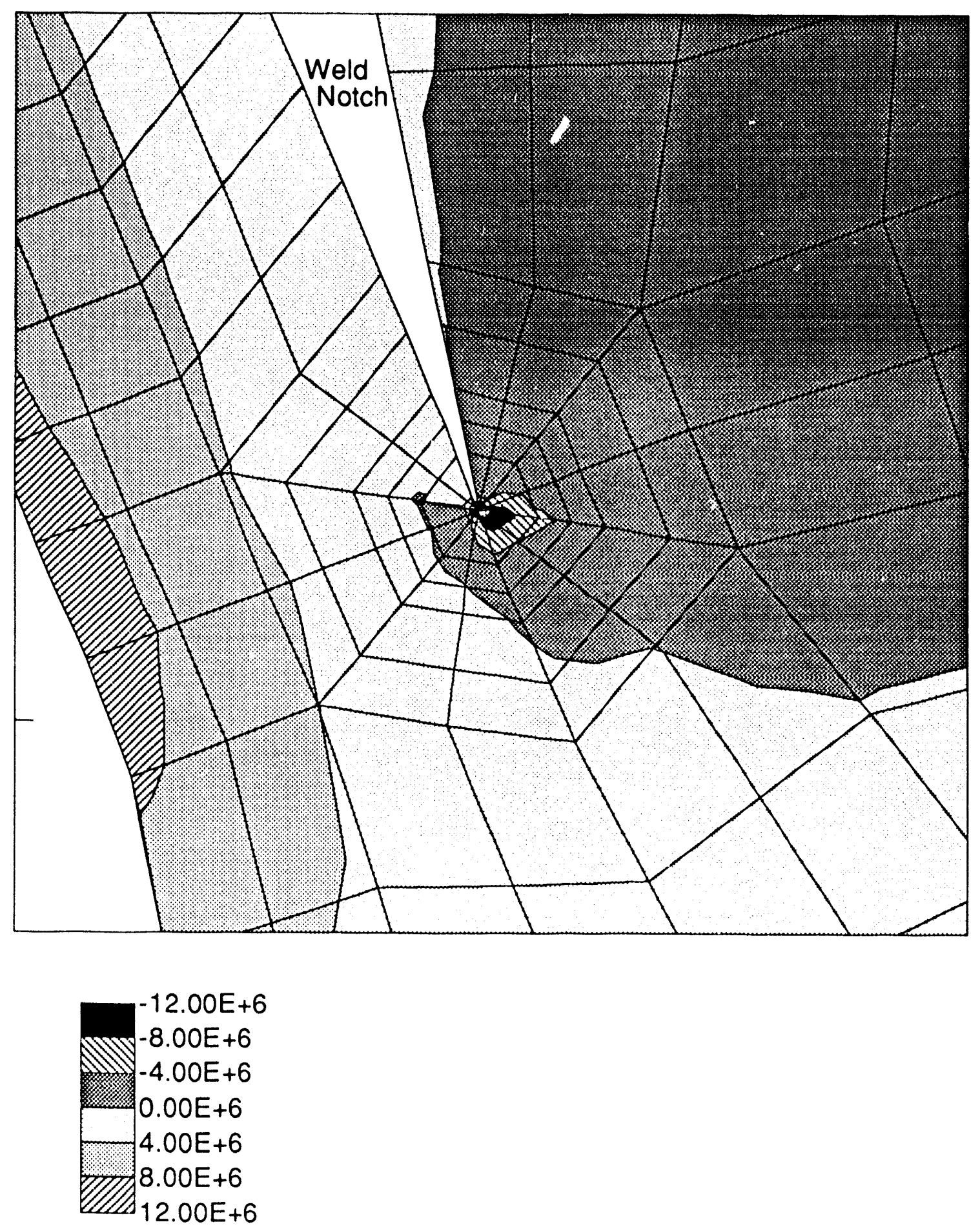

Figure 24. Largest principal stress near the weld discontinuity for the case of thermal loading and $\left(\mathrm{P}_{\mathrm{amb}}-\mathrm{P}_{\mathrm{int}}\right)=32.9 \mathrm{kPa}$ (Case 1$)$. 


\subsubsection{Case 2: On-Sun Structural Loading and No Thermal Loads}

The compressive stress field observed in the previous analysis was expected because the absorber tries to expand more than the aft dome, producing a compressive loading at the seam-weld. To determine the contribution of the structural load to the stress distribution near the weld, the calculation was repeated with the thermal loads removed. Figure 25 is a plot of the circumferential stresses in the inner and outer absorber surfaces :inder these load conditions. When compared to Figure 23, these plots demonstrate that the thermal loads determine the overall stress profile in the receiver. The stress profile in Figure 23 is characterized by the distinctive double hump produced by the incident solar flux distribution shown in Figure 6 . However, this double hump is not present in Figure 25. Note that the average of the inner and outer stresses, the membrane stress, in Figure 25 is nearly the same as that in Figure 23. This indicates that the structural loads generate the membrane stress, while the thermal loads produce a nearly pure bending stress.

The largest principal stresses near the weld notch is plotted in Figure 26 for the structurally loaded receiver with no thermal loads. These stress contours are nearly identical to those for Case 1, indicating that the localized stress distribution near the seam-weld depends more on the internal pressure of the receiver than on the thermal loads. Since the stress distribution ahead of the notch tip is the same with or without thermal loading, this suggests that thermal

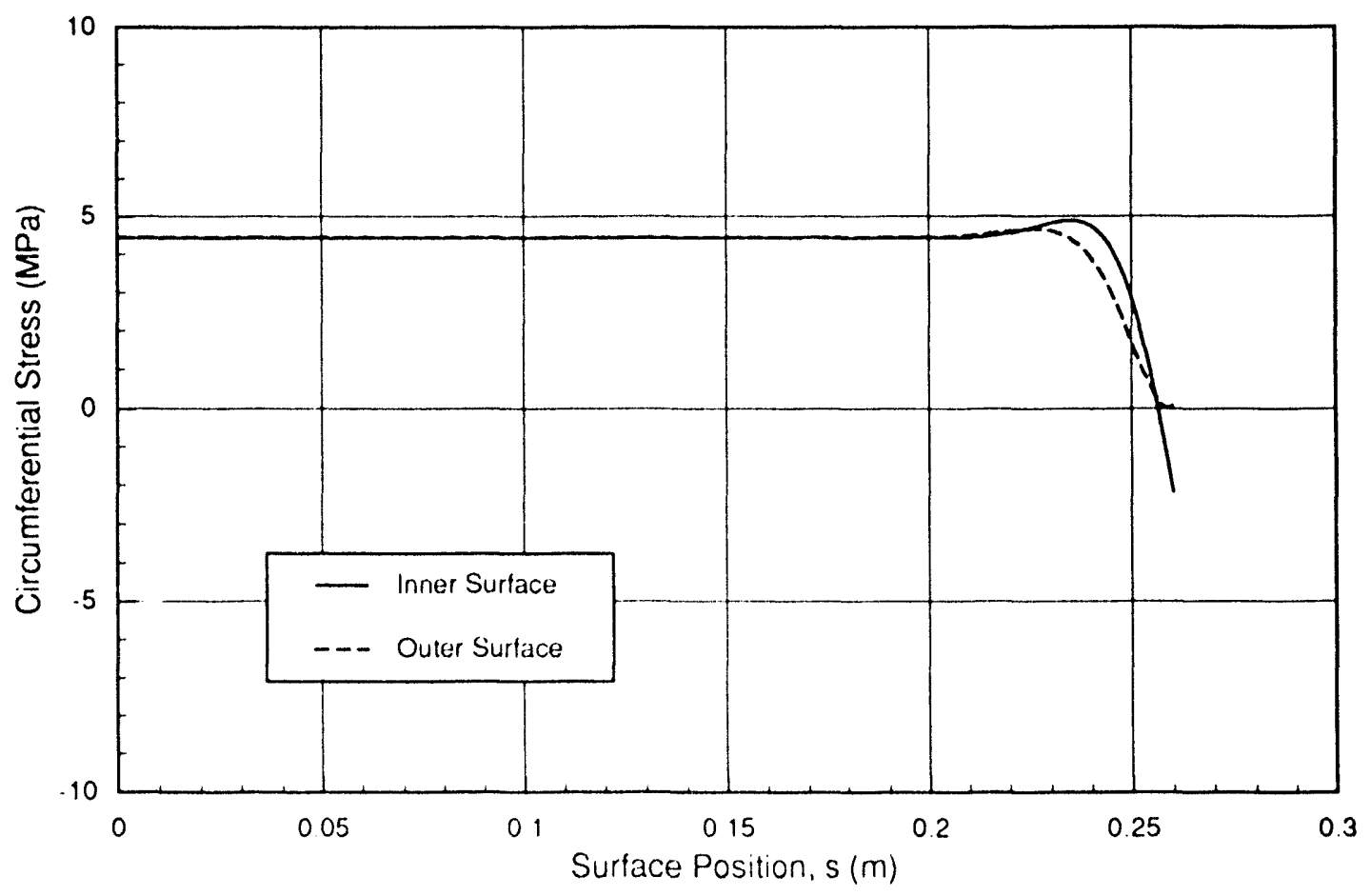

Figure 25. Circumferential stress in absorber for on-sun structural loading and no thermal loads (Case 2). 

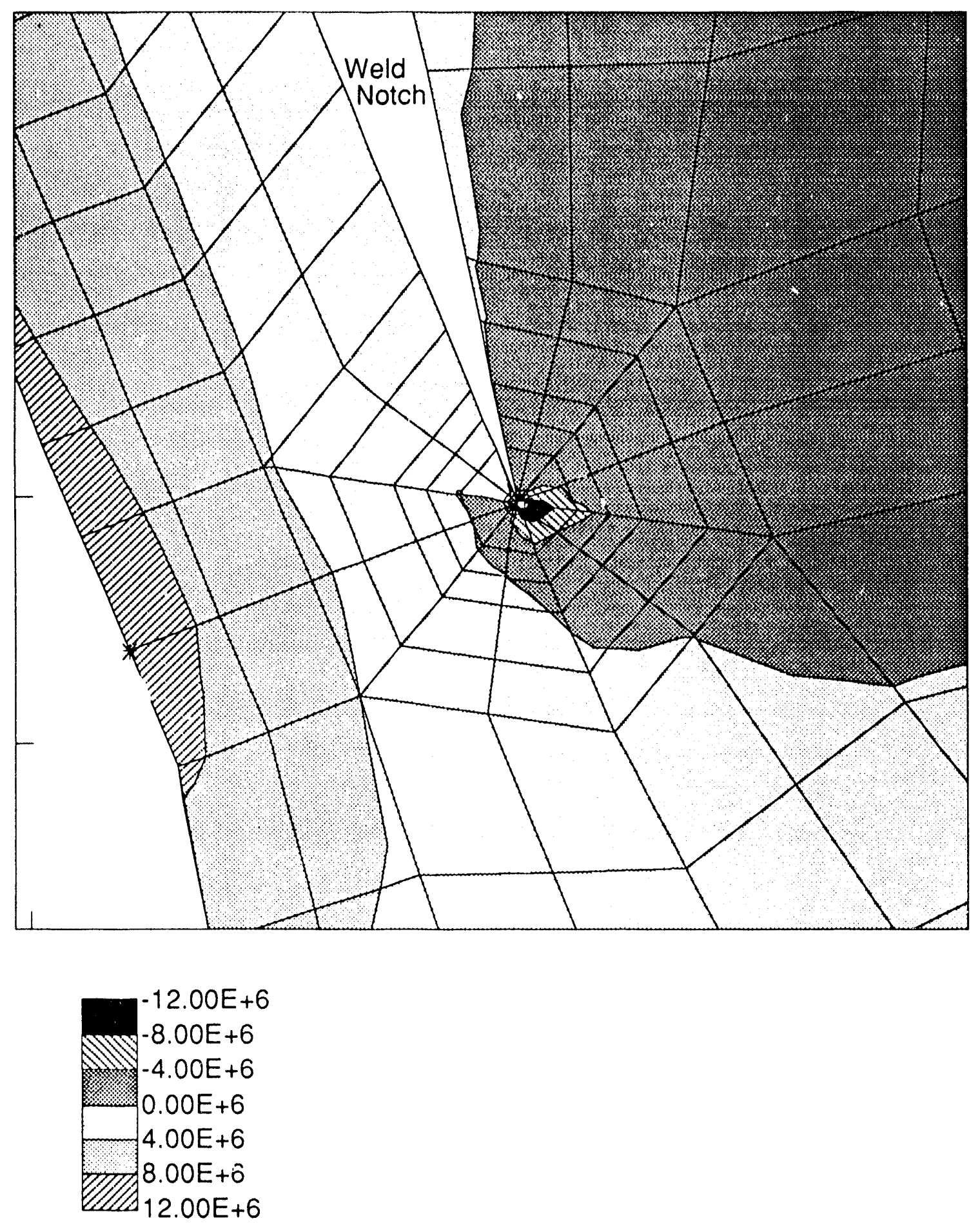

Figure 26. Largest principal stress near the weld discontinuity for the case of no thermal loading and $\left(\mathrm{P}_{\mathrm{amb}}-\mathrm{P}_{\mathrm{im}}\right)=32.9 \mathrm{kPa}$ (Case 2). 
loads need not be considered when calculating $K_{1}$.

\subsubsection{Case 3: Off-Sun Structural Loading with Reversed On-Sun Thermal Loads}

To reverse the thermal loads applied to the reflux pool-boiler receiver during steady state operation, the sign of the cocfficient of thermal expansion was changed. The circumferential stress profile in the absorber with reversed thermal loads is shown in Figure 27 for comparison with Figure 23. The stress profiles are of similar magnitude, but opposite in sign. The inner surface is in compression, while the outer surface is in tension. Again, the plot is characterized by the distinctive double hump produced by the thermal flux distribution shown in Figure 6. This stress profile is an approximation to the off-sun residual stress state after the on-sun thermal stresses have relaxed. A plot of the largest principal stress near the seam-weld notch is shown in Figure 28. Again, the stress field is compressive in the seam-weld ahead of the notch. Crack propagation will not occur into a compressive stress field. Furthermore, the magnitude of the stress distribution near the seam-weld notch is small, with maximum stresses on the order of $24 \mathrm{MPa}(3.48 \mathrm{ksi})$.

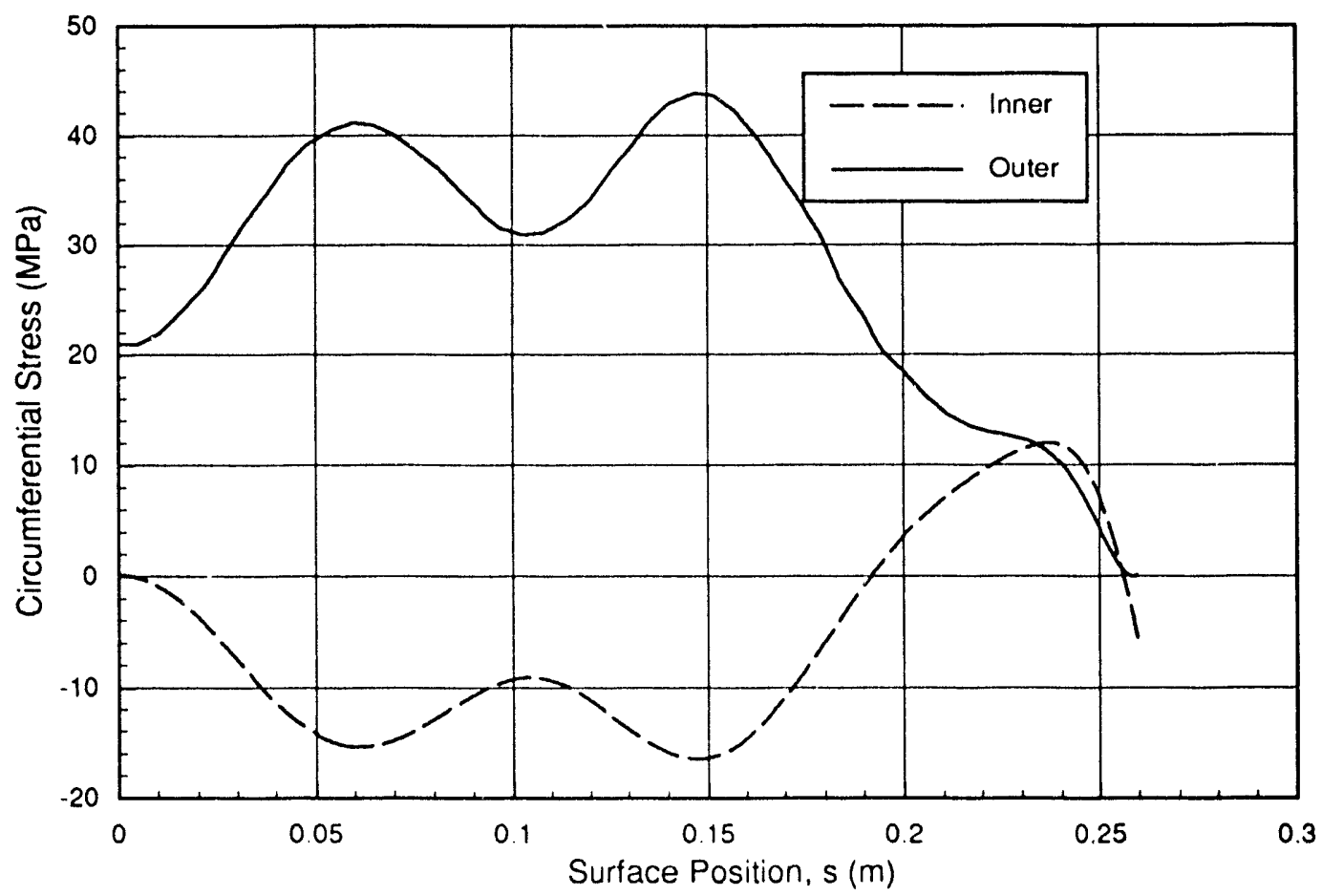

Figure 27. Circumferential stress in the absorber as a function of surface position for offsun structural and reversed thermal loading (Case 3). 

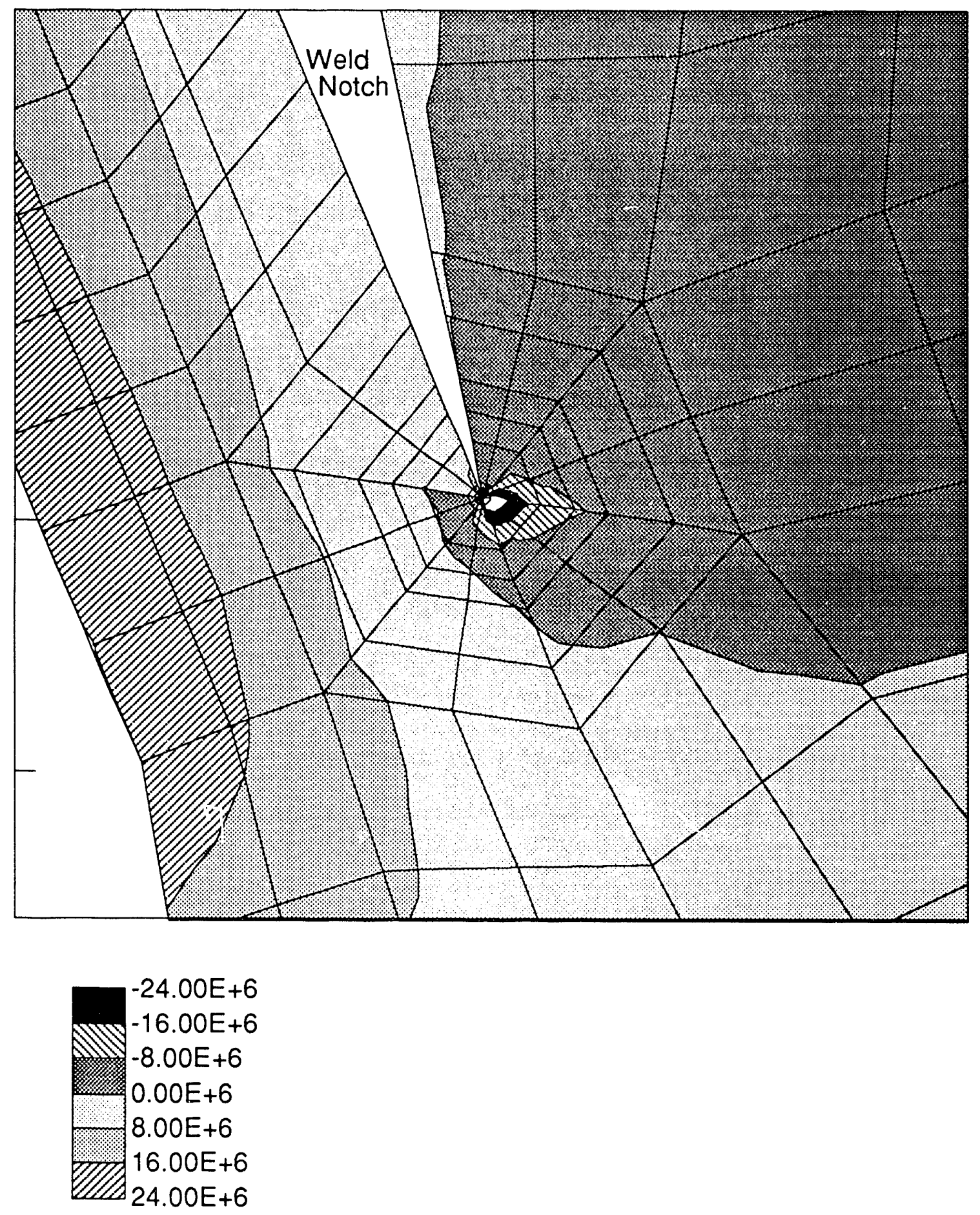

Figure 28. Largest principal stress near the weld discontinuity for the case of reversed thermal loading and $\left(\mathrm{P}_{\text {amb }}-\mathrm{P}_{\text {int }}\right)=84.1 \mathrm{kPa}$ (Case 3$)$. 


\subsubsection{Case 4: Off-Sun Structural Loading with No Thermal Loads}

This particular load case was analyzed to determine (1) the contribution of thermal loading to the seam-weld stress distribution in the previous case and (2) the off-sun load that the receiver is subjected to prior to any stress relaxation. Figure 29 is a plot of the circumferential stress in the absorber for off-sun structural loading and no thermal loads. The average of the inner and outer stresses, the membrane stress, is approximately twice that of the receiver with on-sun structural loading and no thermal loads (see Figure 25). This is due to the higher internal pressure loads generated when the receiver is off-sun. Furthermore, the membrane stress for this load case is approximately the same as that in Figure 27, the case of off-sun structural loading with reversed thermal loads. This again indicates that the structural loads are dominant in determining the membrane stress in the receiver, while the thermal gradients produce nearly pure bending stresses.

The maximum principal stress distribution near the upper seam-weld notch for Case 4 load conditions, illustrated in Figure 30, is nearly identical to that of Case 3 (see Figure 28). This indicates that the stress distribution local to the upper seam-weld notch depends more on the structural loads, which induces a membrane stress, than the thermal loads, which induce pure bending. This again indicates that the stress intensity factor can be calculated neglecting thermal loads.

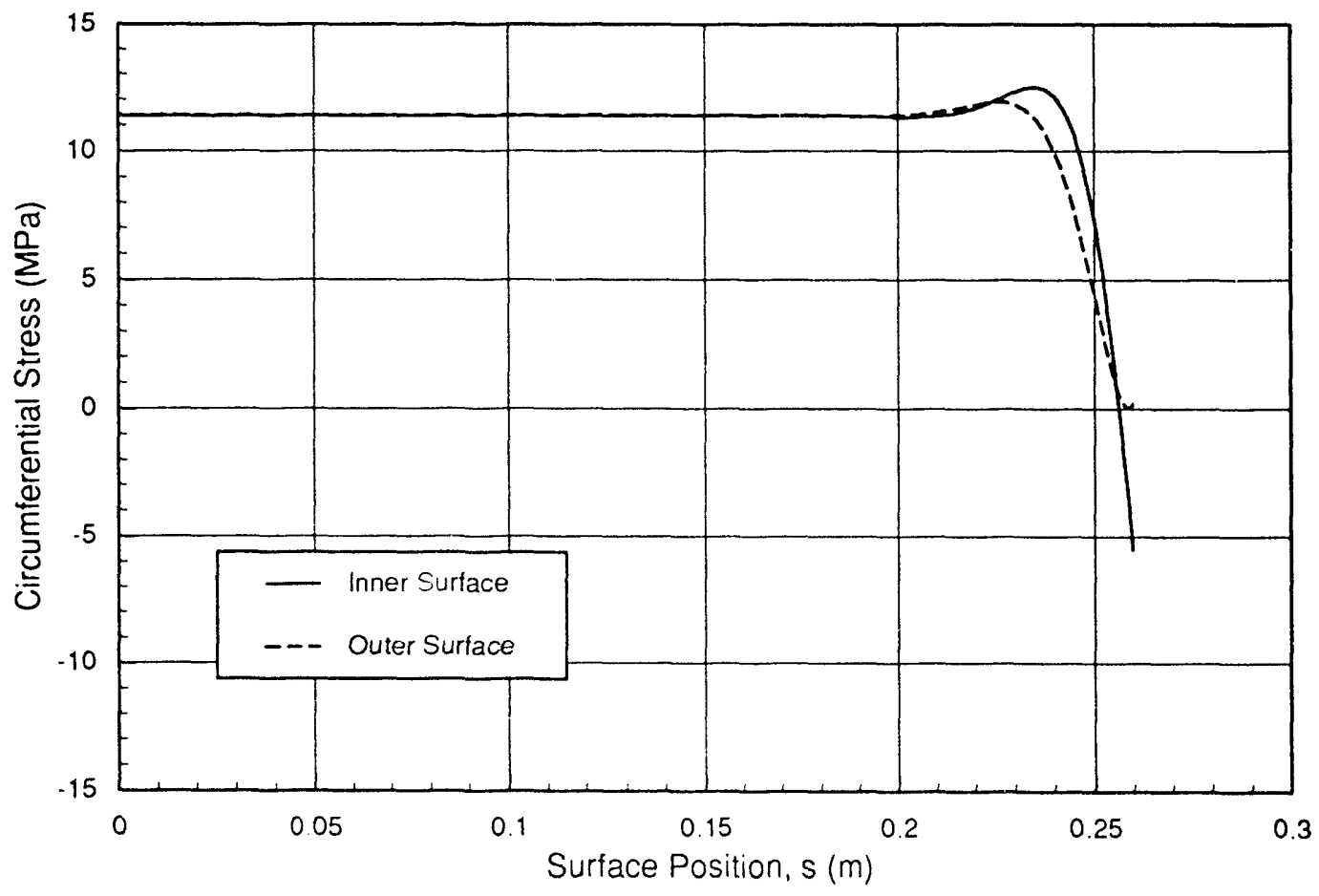

Figure 29. Circumferential stress in the absorber as a function of surface position for the casc of off-sun structural loading and no thermal loads (Case 4). 

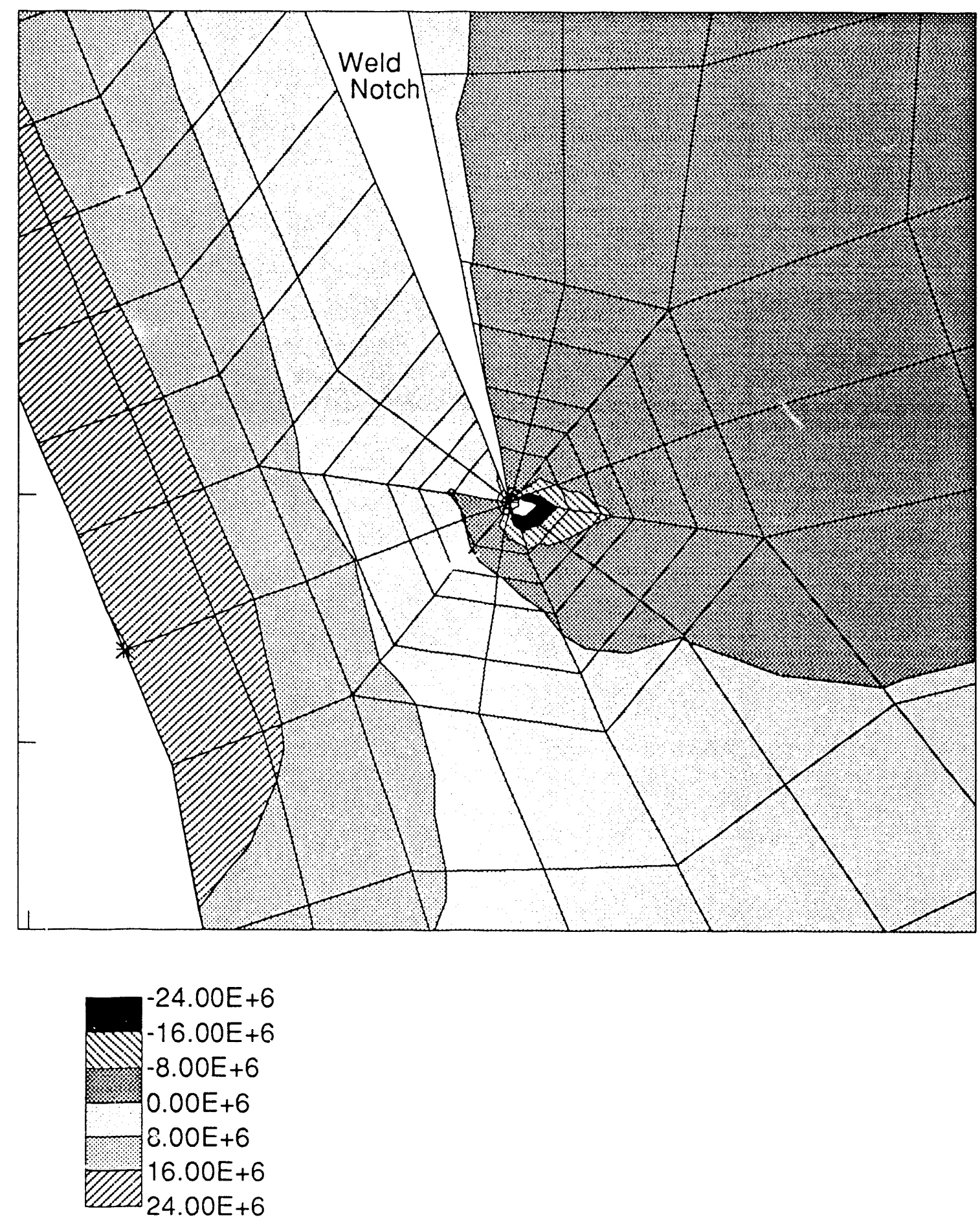

Figure 30. Largest principal stress near the weld discontinuity for the case of no thermal loading and $\left(\mathrm{P}_{\text {amb }}-\mathrm{P}_{\text {imt }}\right)=84.1 \mathrm{kPa}$ (Case 4). 


\subsubsection{Fluctuation of Stress Intensity Factor}

In all four of the cases presented above the stress intensity factor, $\mathrm{K}_{\mathrm{I}}$, was calculated using the J-integral feature in ABAQUS as well as the opening-displacement field equations. Based on inspection of the stress field ahead of the notch in the previous sections, it was concluded that the thermal loads should not contribute significantly to $\mathrm{K}_{\mathrm{I}}$. Thus, any differences in $\mathrm{K}_{\mathrm{I}}$ contributed by the thermal load could be attributed to free thermal expansion of the receiver. In all cases, these methods yielded $\mathrm{K}_{\mathrm{I}}$ values on the order of 0.05 to $0.40 \mathrm{MNm}^{3 / 2}(0.046$ to 0.367 $\mathrm{ksi} \sqrt{\mathrm{in}}$ ) for the upper seam-weld notch. The smaller values of $K_{\mathrm{I}}$ were obtained for $0.5 \mathrm{~atm}$ applied pressure, and the larger for the $1 \mathrm{~atm}$ applied pressure. The best correlation between the J-integral and crack opening methods was obtained for the cases with no thermal loads. As expected, the same parameters were orders of magnitude smaller at the lower seam-weld notch. Based on these calculations, the fluctuation of the stress intensity factor in both seamweld notches is considerably lower than the fatigue-threshold, $\Delta \mathrm{K}_{\mathrm{th}}$, for most stainless steels $\left(6 \mathrm{MNm}^{-3 / 2}\right.$ or $\left.5.5 \mathrm{ksi} \sqrt{\mathrm{in}}\right)$. Furthermore, the plots of the largest principal stress near the seamweld indicate that, for all four cases, the weld notch is always loaded in compression. As previously stated, crack propagation will not occur in a compressive stress field.

\subsection{Comments on Startup Stresses}

The calculations presented in the preceding section indicate that a crack will not propagate into the seam-weld under load conditions cycling between off-sun and on-sun operation. However, the shell analyses indicated that the most severe stress condition at the seam-weld occurred during Step 3 of startup. Much can be inferred by comparing the shell results to the steady state continuum results. The steady state continuum-element results demonstrate that the seam-weld remains in compression. This was also observed in the shell calculations, as shown in Figure 12. During startup (Figure 11), the sheil calculations indicate that the meridional and circumferential stresses near the inner surface of the seam-weld are also in compression, on the order of $70 \mathrm{MPa}$. Although this is significantly higher than the steady state results, the continuum calculations indicate that (1) the stresses are still too small to raise the J-integral values appreciably, and (2) the compressive stress field, though higher, is not conducive to crack growth.

Moreover, the results of the more detailed seam-weld analysis indicate that the structural load, as opposed to the thermal loads, determine the stress state at the crack tip. Since the four load cases presented span the operating pressure range and the receiver operates within this range during startup, it reasons that the results of these calculations should bound the startup conditions as well. 


\section{Conclusions}

Coupled thermal-structural analyses of the reflux pool-boiler receiver were performed to characterize the operating stress stale and to address issues affecting the service life of the receiver. Shell analyses provided int urmation for receiver material selection and design optimization. More detailed continuum element analyses were performed to assess the vulnerability of the seam-weld to fatigue crack growth. Based on these calculations, the following conclusions are made:

- Maximum stresses in the receiver occur 2 minutes into startup (Step 3) due to the uneven temperature distribution across the receiver surface. The stress levels during startup could be reduced if temperatures across the receiver surface could be maintained at a more uniform level.

- Stresses in the 316L SS prototype receiver are near the $100 \mathrm{MPa}$ yield strength of this alloy.

- Because of its higher yield strength, the largest effective stress in the Haynes 230 receiver is less than 39 percent of yield.

- Reducing the aft dome thickness to $1.59 \mathrm{~mm}$ reduces the maximum stress in the receiver by over 25 percent. A further reduction to $0.813 \mathrm{~mm}$ has a small effect on the overall stress profile; however, the seam-weld stresses decrease another 40 percent. A reduction in aft dome thickness to one closer to the absorber thickness should be considered for the next-generation receiver design.

- The stress distribution near the seam-weld notch depends primarily on the structural load created by the pressure difference between the sodium and the surrounding environment rather than the thermal loads due to temperature cycling. Thus, investigations of the seam-weld fatigue toughness need only consider the range of operating pressures between off-sun and on-sun operation.

- The stress intensity factor, computed using the J-integral method and crack openingdisplacement field equations, is significantly below the fatigue threshold for most steels. Furthermore, the crack is always loaded in compression which is not conducive to fatigue crack growth. As a result, the candidate seam-weld investigated in these calculations will not adversely affect the receiver service life. 


\section{References}

1 R. B. Diver, C. E. Andraka, J. B. Moreno, D. R. Adkins, and T. A. Moss, Trends in Dish-Stirling Solar Receiver Designs, Sandia National Laboratories, SAND90-1236C; 25th Intersociety Energy Conversion Engineering Conference, Rerio, Nevada; August, 1990.

2 C. E. Andraka, J. B. Moreno, R. B. Diver, V. Dudley, and K. S. Rawlinson, Reflux PoolBoiler as a Heat-Transport Device for Stirling Engines: On-Sun Test Program Results, Sandia National Laboratories, SAND89-0268C; 25th Intersociety Energy Conversion Engineering Conference, Reno, Nevada; August, 1990.

3 M. K. Neilsen, Solar Receiver Thermal Stress Analysis, memo to J. B. Moreno, Sandia National Laboratories, September 18, 1989.

4 C. M. Stone and E. L. Hoffman, Thermal Stress Analysis of a Sodium Reflux Pool-Boiler Receiver, memo to J. B. Moreno, Sandia National Laboratories, October 3, 1990.

5 E. L. Hoffman and C. M. Stone, Thermal Stress Analysis of a Sodium Reflux Pool-Boiler Receiver Studying the Effects of Nonlinear Material Properties and Reduced Aft Dome Thickness, memo to J. B. Moreno, Sandia National Laboratories, November 29, 1990.

6 E. L. Hoffman, C. M. Stone, and G. W. Wellman, Fatigue-Crack Analysis of a Seam Weld in the Reflux Pool Boiler Receiver, memo to J. B. Moreno, Sandia National Laboratories, January $17,1991$.

7 Hibbitt, Karlsson, and Sorensen, ABAQUS User's Manual, Version 4.8, HKS Inc., 1989.

8 J. B. Moreno, C. E. Andraka, R. B. Diver, W. C. Ginn, V. Dudley, and K. S. Rawlinson, Test Results from a Full-Scale Sodium Reflux Pool-Boiler Solar Receiver, ASME Solar Energy Division Conference, Miami, Florida, April, 1990.

9 J. B. Moreno and C. E. Andraka, Review of Sodium Pool Boiler Design, memo to Distribution, February 8, 1990.

10 Sodium NaK Engineering Handbook Vol. 1, O. J. Faust (ed), Gordon and Breach, 1972.

11 A. C. Ratzel and B. D. Boughton, Circe.001: A computer Code for Analysis of PointFocus Concentrators with Flat Targets, SAND86-1866, Sandia National Laboratories, 1986.

12 S. T. Rolfe and J. M. Barsom, Fracture and Fatigue Control in Structures, PrenticeHall Inc.; Englewood Cliffs, NJ, 1977.

13 M. F. Kanninen and C. H. Popelar, Advanced Fracture Mechanics, Oxford University Press; New York, NY, 1985. 
14 Hibbitt, Karlsson, and Sorensen, ABAQUS Theory Manual, Version 4.8, HKS Inc., 1989.

15 A. P. Gilkey and J. H. Glick, BLOT - A Mesh and Curve Plot Program for the Output of a Finite Element Analysis, SAND88-1432, June 1989. 


\section{Distribution:}

U.S. Department of Energy (5)

Forrestal Building

Code CE-132

1000 Independence Avenue, SW

Washington, DC 20585

Attn:

M. Scheve

S. Gronich

U.S. Department of Energy (2)

Forrestal Building

Code CE-13

1000 Independence Avenue, SW

Washington, DC 20585

Attn: R. Annan

U.S. Department of Energy (2)

Albuquerque Operations Office

P.O. Box 5400

Albuquerque, NM 87115

Attn: G. Tennyson

N. Lackey

U.S. Department of Energy

San Francisco Operations Office

1333 Broadway

Oakland, CA 94612

Attn: R. Hughey

Acurex Corporation (2)

555 Clyde Avenue

Mountain View, CA 94039

Attn: J. Schaefer

H. Dehne

Advanced Thermal Systems

7600 East Arapahoe

Suite 319

Englewood, CO 80112

Attn: D. Gorman

Arizona Public Service Company

P.O. Box 21666

Phoenix, AZ 85036

Attn: J. McGuirk

Arizona Solar Energy Office

Dept. of Commerce

$1700 \mathrm{~W}$. Washington, 5th Floor

Phoenix, AZ 85007

Attn: F. Mancini
Australian National University

Department of Engineering

Physics

P. O. Box 4

Canberra ACT 2600 AUSTRALIA

Attn: S. Kaneff

Barber-Nichols Engineering

6325 West 55th Avenue

Arvada, CO 80002

Attn: R. Barber

Battelle Pacific Northwest Laboratory (2)

P.O. Box 999

Richland, WA 99352

Attn: T. A. Williams

D. Brown

BDM Coporation

1801 Randolph Street

Albuquerque, NM 87106

Attn: W. Schwinkendorf

Bechtel National, Inc. (2)

50 Beale Street

$50 / 15 \mathrm{D} 8$

P. O. Box 3965

San Francisco, CA 94106

Attn: P. DeLaquil

S. Nickovich

Black \& Veatch Consulting Engineers

P.O. Box 8405

Kansas City, MO 64114

Attn: J. C. Grosskreutz

Tom Brumleve

1512 Northgate Road

Walnut Creek, CA 94598

California Energy Commission

1516 Ninth Street, M-S 43

Sacramento, CA 95814

Attn: A. Jenkins

California Polytechnic University

Dept. of Mechanical Engineering

Pomona, CA 91768

Attn: W. Stine 
California Public Utilities Com.

Resource Branch, Room 5198

455 Golden Gate Avenue

San Francisco, CA 94102

Attn: T. Thompson

Cummins Engine Co. (2)

MC 60125

P. O. Box 3005

Columbus, IN 47202-3005

Attn: R. Kubo

Dan Ka

3905 South Mariposa

Englewood, CO 80110

Attn: D. Sallis

DLR

Pfaffenwaldring 38-40

7000 Stuttgart 80 GERMANY

Attn: R. Buck

Electric Power Research Institute

P.O. Box 10412

Palo Alto, CA 94303

Attn: J. Schaeffer

Energy Research Centre (2)

R. S. Phy. Sc.

Australian National University

Canberra ACT 2601 AUSTRALIA

Attn: K. Inall

Energy Technology Engr. Center

Rockwell International Corp.

P. O. Box 1449

Canoga Park, CA 91304

Attn: W. Bigelow

ENTECH, Inc.

P. O. Box 612246

DFW Airport, TX 75261

Attn: R. Walters

Florida Solar Energy Center

300 State Road 401

Cape Canaveral, FL 32920

Attn: Library

Ford Aerospace

Ford Road

Newport Beach, CA 92663

Attn: R. Babbe
Foster Wheeler Solar Development

Corporation (2)

12 Peach Tree Hill Road

Livingston, NJ 07039

Attn: M. Garber

R. Zoschak

Garrett Turbine Engine Co.

111 South 34th Street

P. O. Box 5217

Phoenix, AZ 85010

Attn: E. Strain

Georgia Power (2)

7 Solar Circle

Shenandoah, GA 30265

Attn: W. King

Harris Corporation (2)

Government and Aerospace Systems Divi-

sion

P. O. Box 9400

Melbourne, FL 32902

Attn: K. Schumacher

Industrial Solar Technologies

5775 West 52nd Avenue

Denver, CO 80212

Attn: R. Gee

Institute of Gas Technology

34245 State Street

Chicago, IL 60616

Attn: Library

Jet Propulsion Laboratory

4800 Oak Grove Drive

Pasadena, CA 91109

Attn: M. Alper

LaJet Energy Company (2)

P. O. Box 3599

Abilene, TX 79604

Attn: M. McGlaun

L'Garde, Inc. (2)

1555 Placentia Avenue

Newport Beach, CA 92663

Attn: M. Thomas

J. Williams 
Lawrence Berkeley Laboratory

MS 90-2024

One Cyclotron Road

Berkeley, CA 94720

Attn: A. Hunt

Luz International (2)

924 Westwood Blyd.

Los Angeles, CA 90024

Attn: D. Kearney

3M-Energy Control Products (2)

207-1W 3M Center

St. Paul, MN 55144

Attn: R. Dahlen

McDonnell-Douglas Astronautics Company

(3)

5301 Bolsa Avenue

Huntington Beach, CA 92647

Attn: R. L. Gervais,

J. Rogan,

D. Steinmeyer

Mechanical Technology, Inc. (2)

968 Albany Shaker Road

Latham, NY 12110

Attn: G. Dochat

J. Wagner

Meridian Corporation

4300 King Street

Alexandria, VA 22302

Attn: D. Kumar

NASA Lewis Research Center (4)

21000 Brook Park Road

Cleveland, $\mathrm{OH} 44135$

Attn: R. Shaltens

J. Schrieber

Nevada Power Co.

P. O. Box 230

Las Vegas, NV 89151

Attn: Mark Shank

New Mexico Solar Energy Institute

New Mexico State University

Box 3SOL

Las Cruces, NM 88003
Northern Research and Engineering Corp.

39 Olympia Avenue

Woburn, MA 01801-2073

Attn: J. Kesseli

Pacific Gas and Electric Company (2)

3400 Crow Canyon Road

San Ramon, CA 94526

Attn: G. Braun

J. Iannucci

Power Kinetics, Inc. (10)

415 River Street

Troy, NY 12180-2822

Attn: W. E. Rogers

Renewable Energy Institute

1001 Connecticut Ave. NW

Suite 719

Washington, DC 20036

Attn: K. Porter

Rocketdyne Division

6633 Canoga Park Ave.

Canoga Park, CA 91304

Attn: W. Marlatt

San Diego Gas and Electric Company

P.O. Box 1831

San Diego, CA 92112

Attn: R. Figueroa

Southern California Edison (3)

P. O. Box 800

Rosemead, CA 91770

Attn: P. Skvarna

Schlaich, Bergermann \& Partner

Hohenzollernstr. 1

D - 7000 Stuttgart 1 GERMANY

Attn: W. Schiel

Sci-Tech International

Advanced Alternative Energy Solutions

5673 W. Las Positas Boulevard

Suite 205

P.O. Box 5246

Pleasanton, CA 84566

Attn: U. Ortabasi 
Science Applications International Corporation (2)

10343 Roselle Street, Suite G

San Diego, CA 92121

Attn: $\quad K$. Beninga

Solar Energy Industries Assoc. (2)

777 North Capitol St. NE

Suite 805

Washington, D.C. 20002

Attn:

S. Sklar

K. Sheinkopf

Solar Energy Research Institute (6)

1617 Cole Boulevard

Golden, CO 80401

Attn: B. Gupta

L. M. Murphy

G. Jorgensen

T. Wendelin

A. Lewandowski

M. Bohn

Solar Kinetics, Inc. (2)

P.O. Box 540636

Dallas, TX 75354-0636

Attn: J. A. Hutchison

P. Schertz

Solar Power Engineering Company

P.O. Box 91

Morrison, CO \&u465

Attn: H. Wroton

Solar Steam

P. O. Box 32

Fox Island, WA 98333

Attn: D. Wood

SRS Technologies

990 Explorer Blvd., NW

Huntsville, AL 35806

Attn: R. Bradford

Stirling Technology Company (2)

2952 George Washington Way

Richland, WA 99352

Attn: Mr. Maurice A. White

Stirling Thermal Motors

2841 Boardwalk

Ann Arbor, MI 48104

Attn: T. Godett
Sunpower, Inc.

6 Byard Street

Athens, $\mathrm{OH}$ 457(01

Attn: W. Beale

Tom Tracey

6922 South Adams Way

Littleton, CO 80122

Thermacore, Inc. (2)

780 Eden Road

Lancaster, PA 17601

Attn: Mr. Donald Ernst

United Solar Tech, Inc.

3434 Martin Way

Olympia, WA 98506

Attn: R. Kelley

University of Chicago

Enrico Fermi Institute

5640 Ellis Avenue

Chicago, IL 60637

Attn: J. O'Gallagher

University of Houston

Solar Energy Laboratory

4800 Calhoun

Houston, TX 77704

Attn: L. Vant-Hull

J. Richardson

University of Minnesota

Dept. of Mechanical Engineering

111 Church St., SE

Minneapolis, MN 55455

Attn: E. A. Fletcher

University of New Mexico (2)

Dept. of Mechanical Engineering

Albuquerque, NM 87131

Attn: M. W. Wilden

W. A. Gross

University of Utah

Mechanical and Industrial Engineering

Salt Lake City, UT 84112

Attn: B. Boehm

Eric Weber

302 Caribbean Lane

Phoenix, AZ 85022 
WG Associates

6607 Stonebrook Circle

Dallas, TX 75240

Attn: V. Goldberg

Sandia Internal Distribution:

1425

J. H. Biffle

1510

J. C. Cummings

1511 J. S. Rottler

1512 A. C. Ratzel

1513 D. R. Adkins

1513 R. D. Skocypec

1514 H. S. Morgan

1514 E. L. Hoffman (10)

1514 M. K. Neilsen

1514 C. M. Stone

1514 G. W. Wellman

$1500 \mathrm{~A}$ L. W. Davison

1540 J. R. Asay

1544 J. R. Asay (Actg.)

1545 D. R. Martinez

1550 C. W. Peterson

1832 J. A. Van Den Avyle

1833 G. A. Knorovsky

1840 R. E. Loehman

1846 D. H. Doughty

1846 C. S. Ashley

3141-1 S. A. Landenberger (5)

3151 G. C. Claycomb (3)

3145 Document Processing for DOE/ OSTI (8)

6000 V. L. Dugan, Acting

6200 B. W. Marshall, Acting

6210 J. T. Holmes, Acting

6215 A. A. Heckes

6215 C. P. Cameron, Actg (25)

6215 K. S. Rawlinson

6216 C. E. Tyner

6216 D. J. Alpert
6216 T. R. Mancini

6217 C. E. Andraka

6217 P. C. Klimas

6217 R. B. Diver

6217 J. B. Moreno

6220 D. G. Schueler

6223 G. J. Jones

6224 A. R. Mahoney

7470 J. L. Ledman

7476 F. P. Gerstle

7476 S. T. Reed

8523-2 Central Technical Files

8524 J. A. Wackerly 

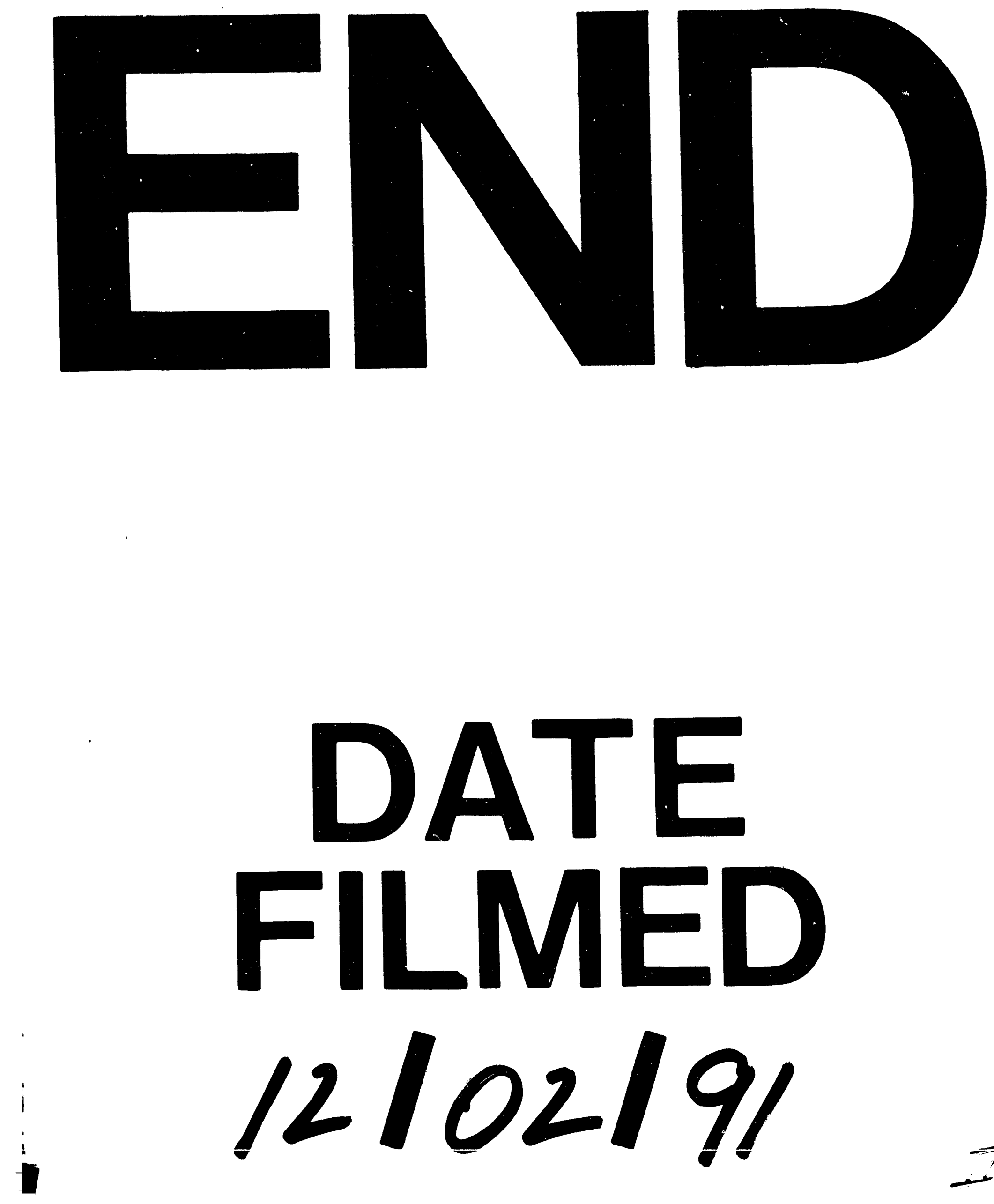